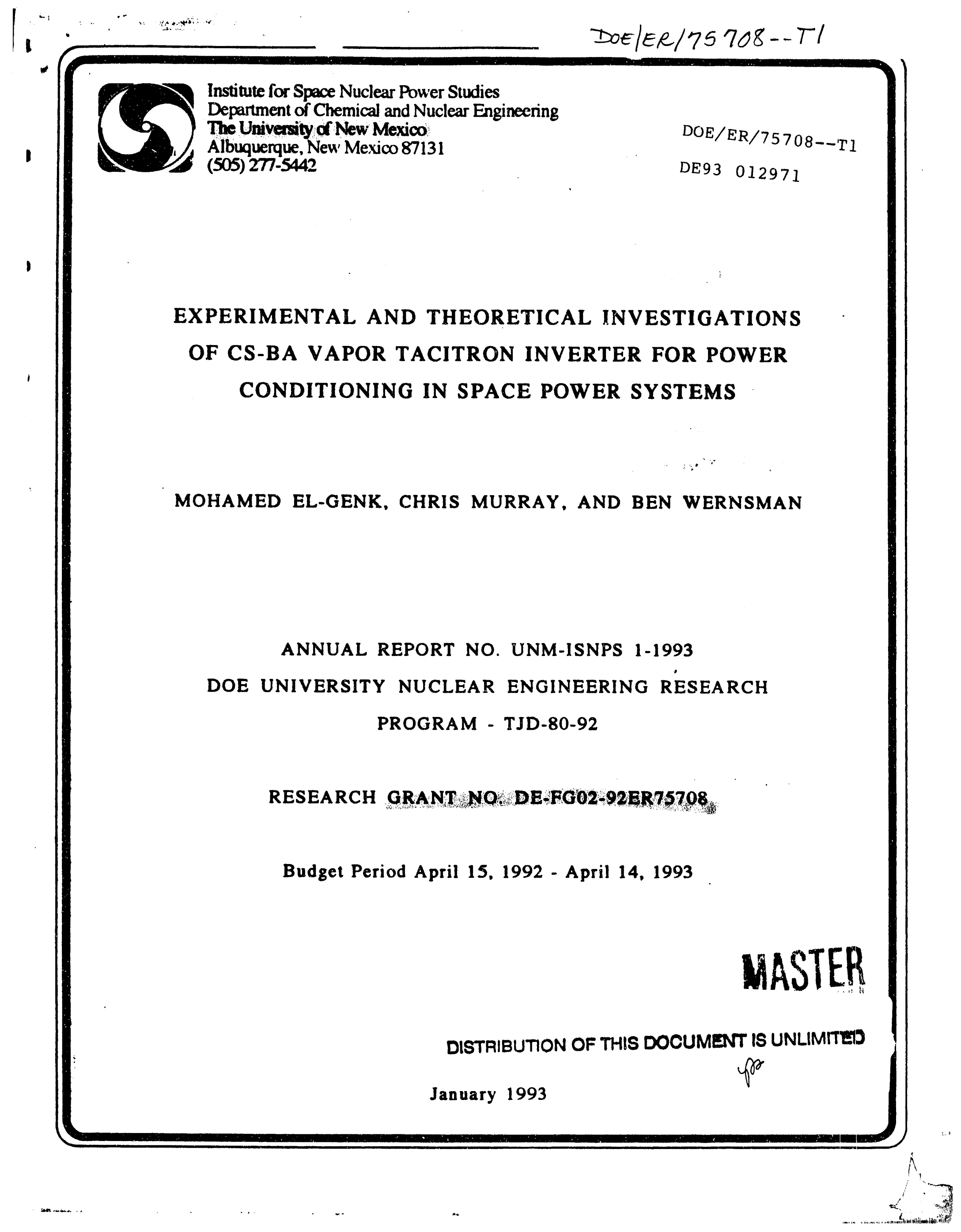




\section{TABLE OF CONTENTS}

Page

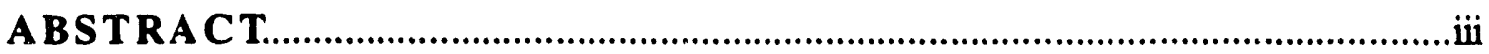

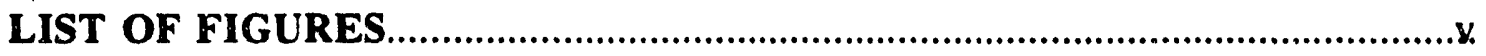

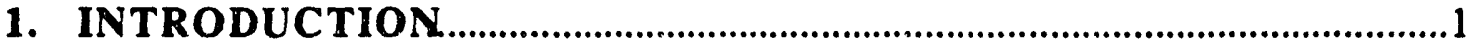

2. DESCRIPTION OF Cs-Ba TACITRON TEST FACILIT.Y.................3

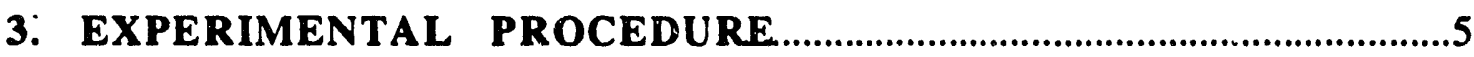

4. EXPERIMENTAL RESULTS OF CS-BA TACITRON SWITCH...6

4.1 Establishment of Discharge Equilibrium Conditions ....................................6

4.2 Voltage Drop Influence on the Equilibrium Conditions.................................12

4.3 Ignition in the Breakdown Mode .................................................................18

4.4 Stable and Unstable Current Modulation Regimes...........................................18

4.5 Discharge Ignition During Current Modulation.............................................25

5. Cs-Ba TACITRONS IN AN INVERTER CONFIGURATION............31

5.1 Cs-Ba Tacitron Inverter Operating in the Thyratron Mode ...............................32

5.2 Cs-Ba Tacitron Inverter Operating in the Tacitron Mode..................................35

5.2.1 Inverter Characteristics with the Large Aperture Grid ......................37

5.2.2 Inverter Characteristics with the Small Aperture Grid......................43

6. SUMMARY AND CONCLUSIONS........................................................

ACKNOWLEDGEMENTS.....................................................................

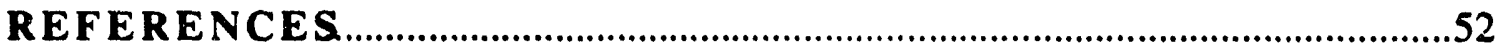

\section{DISCLAIMER}

This report was prepared as an account of work sponsored by an agency of the United States Government. Neither the United States Government nor any agency thereof, nor any of their employees, makes any warranty, express or implied, or assumes any legal liability or responsibility for the accuracy, completeness, or usefulness of any information, apparatus, product, or process disclosed, or represents that its use would not infringe privately owned rights. Reference herein to any specific commercial product, process, or service by trade name, trademark, manufacturer, or otherwise does not necessarily constitute or imply its endorsement, recommendation, or favoring by the United States Government or any agency thereof. The views and opinions of authors expressed herein do not necessarily state or reflect those of the United States Government or any agency thereof. 


\title{
EXPERIMENTAL AND THEORETICAL INVESTIGATIONS OF Cs-Ba VAPOR TACITRON INVERTER FOR POWER CONDITIONING IN SPACE POWER SYSTEMS
}

\begin{abstract}
The operation characteristics of the Cs-Ba tacitron as a switch are investigated experimentally in three modes: (a) breakdown mode, (b) I-V mode, and (c) current modulation mode. The switching frequency, grid potentials for ignition and extinguishing of discharge, and the $\mathrm{Cs}$ pressure and emission conditions ( $\mathrm{Ba}$ pressure and emitter temperature) for stable current modulation are determined. The experimental data is also used to determine the off-time required for successful ignition, and the effects of the aiorementioned operation parameters on the ignition duty cycle threshold for stable modulation. Operation parameters measured include switching frequency up to $20 \mathrm{kHz}$, hold-off voltage up to $180 \mathrm{~V}$, current densities in excess of $15 \mathrm{~A} / \mathrm{cm}^{2}$, switch power density of $1 \mathrm{~kW} / \mathrm{cm}^{2}$, and a switching efficiency in excess of $90 \%$ at collector voltages greater than $30 \mathrm{~V}$. The voltage drop strongly depends on the Cs pressure and to a lesser extent on the emission conditions. Increasing the Cs pressure and/or the emission current lowers the voltage drop, however, for the same initial Cs pressure and emission conditions, the voltage drop in the I-V mode is usually lower than that during current modulation. As long as the discharge current is kept lower that the emission current, the voltage drop during stable current modulation could be as low as $3 \mathrm{~V}$.

Experiments were also conducted which demonstrated that an inverter could be configured by connecting two Cs-Ba tacitrons in a push-pull mode with alternating voltage grid control. The inverter characteristics demonstrated in the thyratron mode include discharge currents up to $20 \mathrm{~A}$, collector voltage of $30 \mathrm{~V}$, conduction voltage drop less than $2.5 \mathrm{~V}$, and modulation frequencies up to $10 \mathrm{kHz}$. In the tacitron mode, the inverter operated at a discharge current of up to $3.5 \mathrm{~A}$, collector voltage of $25 \mathrm{~V}$, conduction voltage drop of $3-3.5 \mathrm{~V}$, and modulation frequencies up to $20 \mathrm{kHz}$. When the grid aperture diameter was reduced from 0.8 to $0.4 \mathrm{~mm}$, it was possible to
\end{abstract}


operate the inverter at discharge currents up to $13.5 \mathrm{~A}$, collector voltage of $24 \mathrm{~V}$ and a conduction voltage drop of $4 \mathrm{~V}$. 


\section{LIST OF FIGURES}

Page

Figure 1. Schematic Cross-Section of the Cs-Ba Tacitron..............................................4

Figure 2. Discharge Current, Forward Voltage Drop and Ion Current to the Grid Illustrating the Time to Reach Equilibrium During the Discharge. .9

Figure 3. Measured Signals Illustrating the Conditions of the Cs-Ba Tacitron During the Breakdown Mode of Operation

Figure 4. Fffect of Increasing Emitter Temperature on Discharge Current and Forward Voltage Drop in the I-V Mode....

Figure 5. Effect of Increasing Barium Pressure on Discharge Current and Forward Voltage Drop in the I-V Mode.

Figure 6. Effect of Increasing Cesium Pressure on Discharge Current and Forward Voltage Drop in the I-V Mode.

Figure 7. Effect of Emitter Temperature on the Grid Potential for Ignition in the Breakdown Mode.

Figure 8. Typical Extinguishing and Ignition Characteristics During Stable Current Modulation at $5 \mathrm{kHz}\left(\mathrm{T}_{\mathrm{E}}=1233^{\circ} \mathrm{C}, \mathrm{T}_{\mathrm{C}}=583^{\circ} \mathrm{C}, \mathrm{T}_{\mathrm{g}}=585^{\circ} \mathrm{C}, \mathrm{T}_{\mathrm{Cs}}=151^{\circ} \mathrm{C}\right.$, and $\mathrm{T}_{\mathrm{Ba}}=530^{\circ} \mathrm{C}$ ).

Figure 9. Typical Extinguishing and Ignition Characteristics During Unstable Current Modulation.

Figure 10. Effect of Ignition Grid Potential on Duty Cycle.

Figure 11. Effect of Cesium Reservoir Temperature on the Off-Time During Current Modulation.

Figure 12. Comparison of $\mathrm{P}_{\text {gap }} \mathrm{d}$ Values for Ignition in the Breakdown and Current Modulation Modes.

Figure 13. Inverter Circuit for Thyratron Mode Operation.

Figure 14. Voltages and Currents for the Top and Bottom Tacitrons While Operating in the Thyratron Mode $\left(\mathrm{T}_{\mathrm{Cs}}=143^{\circ} \mathrm{C}, \mathrm{T}_{\mathrm{Ba}}=556^{\circ} \mathrm{C}\right.$, and $\mathrm{f}_{\mathrm{g}}=2.7 \mathrm{kHz}$ ). 
Figure 15. Voltage and Current from the Pulse Transformer While Operating the Inverter in the Thyratron Mode, (a) $\mathrm{f}_{\mathrm{g}}=2.7 \mathrm{kHz}$ and

(b) $f_{g}=10.6 \mathrm{kHz}$

Figure 16. Voltages and Currents for the Top and Bottom Tacitrons While Operating in the Tacitron Mode $\left(\mathrm{T}_{\mathrm{Cs}}=137^{\circ} \mathrm{C}, \mathrm{T}_{\mathrm{Ba}}=554^{\circ} \mathrm{C}\right.$, and $\left.\mathrm{f}_{\mathrm{g}}=3.97 \mathrm{kHz}\right) \ldots \ldots . .38$

Figure 17. Voltage and Current from the Pulse Transformer While Operating the Inverter in the Tacitron Mode, (a) $f_{g}=10.6 \mathrm{kHz}$ and (b) $f_{g}=20 \mathrm{kHz}$.

Figure 18. Measured Voltage and Current Signals with the Large Aperture Grid While Operating in the Tacitron Mode $\left(\mathrm{T}_{\mathrm{Cs}}=135^{\circ} \mathrm{C}, \mathrm{T}_{\mathrm{Ba}}=575^{\circ} \mathrm{C}\right.$, and $f_{g}=6.5 \mathrm{kHz}$ ).

Figure 19. Measured Voltage and Current Signals with the Large Aperture Grid at the Output of the Step-Up Pulse Transformer While Operating in the Tacitron Mode $\left(\mathrm{T}_{\mathrm{Cs}}=135^{\circ} \mathrm{C}, \mathrm{T}_{\mathrm{Ba}}=575^{\circ} \mathrm{C}\right.$, and $\left.\mathrm{f}_{\mathrm{g}}=6.5 \mathrm{kHz}\right) \ldots \ldots . .41$

Figure 20. Measured Voltage and Current Signals with the Large Aperture Grid While Operating in the Tacitron Mode $\left(\mathrm{T}_{\mathrm{Cs}}=137^{\circ} \mathrm{C}, \mathrm{T}_{\mathrm{Ba}}=554^{\circ} \mathrm{C}\right.$, and $\mathrm{f}_{\mathrm{g}}=20 \mathrm{kHz}$ ).

Figure 21. Measured Voltage and Current Signals with the Small Aperture Grid While Operating in the Tacitron Mode $\left(\mathrm{T}_{\mathrm{Cs}}=138^{\circ} \mathrm{C}, \mathrm{T}_{\mathrm{Ba}}=552^{\circ} \mathrm{C}\right.$, and $f_{g}=6.5 \mathrm{kHz}$ ).

Figure 22. Measured Voltage and Current Signals with the Small Aperture Grid at the Output of the Step-Up Pulse Transformer While Operating in the Tacitron Mode $\left(\mathrm{T}_{\mathrm{Cs}}=138^{\circ} \mathrm{C}, \mathrm{T}_{\mathrm{Ba}}=552^{\circ} \mathrm{C}\right.$, and $\left.\mathrm{f}_{\mathrm{g}}=6.5 \mathrm{kHz}\right) \ldots \ldots . .45$

Figure 23. Measured Voltage and Current Signals with the Small Aperture Grid While Operating in the Tacitron Mode $\left(\mathrm{T}_{\mathrm{Cs}}=139^{\circ} \mathrm{C}, \mathrm{T}_{\mathrm{Ba}}=551^{\circ} \mathrm{C}\right.$, and $\mathrm{f}_{\mathrm{g}}=20 \mathrm{kHz}$ ).

Figure 24. Measured Voltage and Current Signals with the Small Aperture Grid at the Output of the Step-Up Pulse Transformer While Operating in the Tacitron Mode $\left(\mathrm{T}_{\mathrm{Cs}}=139^{\circ} \mathrm{C}, \mathrm{T}_{\mathrm{Ba}}=551^{\circ} \mathrm{C}\right.$, and $\left.\mathrm{f}_{\mathrm{g}}=20 \mathrm{kHz}\right)$ 


\section{INTRODUCTION}

Space nuclear power systems are being designed to supply low voltage/high current DC electrical power in the range of a few tens to hundreds of kilowatts to support a host of civilian and military missions. The output power of these systems is preconditioned to a low voltage/high current AC signal using Solid-State Inverters (SSIs). Although these inverters have high switching efficiencies (>98\%) and are relatively light weight, they are vulnerable to high temperatures $(>500 \mathrm{~K})$ and to nuclear radiation. High temperatures cause material loss by sublimation, hence shortening the lifetime of SSIs, and high fluxes of fast neutrons and gamma . rays cause malfunctions due to single and multiple event upsets. In case of minor upsets the recovery time of SSIs is very long, on the order of milliseconds. Both shielding and separation distance from nuclear reactors are used to provide a tolerable radiation environment at a mass penalty. Therefore, it is desirable to develop inverters that are compatible with high temperature and nuclear radiation environments, have a relatively low mass, a high efficiency, a high modulation frequency, and a long operation lifetime.

A cesium (Cs)-barium (Ba) vapor thermionic triode switch with complete grid control called "tacitron" could satisfy the requirements listed above. Unlike the gas discharge thyratron and hydrogen tacitrons, the $\mathrm{Cs}-\mathrm{Ba}$ tacitron has a significantly lower voltage drop (on the order of 3-3.5 $\mathrm{V}$ compared to about $100 \mathrm{~V}$ for the other gas discharge devices mentioned). This attribute makes the Cs-Ba tacitron inverters suitable for low voltage current sources, such as space nuclear reactor power systems.

The tacitron employs a low pressure cesium and barium vapor mixture (pressure $-10^{-3}$ torr) in the interelectrode gap and has a large gap size; hence, precluding a possibility of a gap closure and short circuiting the electrodes during its operation lifetime. The Cs vapor neutralizes the space charge in the interelectrode gap, while the Ba vapor, adsorbed onto the surface of the electrodes, lowers the work function and increases the emission current density. Because thermal and/or radiation exposure are unlikely to degrade operation, the tacitron is inherently thermal and radiation hard. 
The spontaneous current interruption of grid-controlled switching devices filled with Cs-Ba vapor mixtures has been previously studied by Kaibyshev et al., ${ }^{1}$ Kaibyshev and Kuzin, ${ }^{2}$ and Kaplan et al..3,4 It was shown that the discharge current can be interrupted spontaneously when it reaches a critical value. Several hypothesis have been suggested in the past to explain this phenomena, which include: (1) a reduction in the neutral gas density at high current densities, which leads to the formation of a charged double sheath at constrictions in the discharge channel, such as a grid aperture;5,6 (2) a pronounced inhomogeneity within the grid control elements in the discharge volume; ${ }^{7}$ and (3) a depletion of neutrals due to the removal of ions when the plasma is highly ionized. $2,8 \cdot 10$

At high emission current densities, the plasma in the Cs-Ba tacitron could be highly ionized; therefore, most of the heavy components are ions. 2,11,12 During the conduction state of the device the leakage of ions to the surrounding reduces the concentration of heavy components in the gap, which under certain conditions causes the discharge process to become unstable and selfextinguish.2,8-10 If the ionization fraction is high, an instability can be elicited by applying a negative potential to the grid with relatively large apertures. In this case, in order to successfully extinguish the discharge the on-time should be sufficiently long, which affects the switching frequency of the tacitron. Another factor which affects the switching frequency of the Cs-Ba tacitron during stable current modulation is the off-time needed to replenish the Cs atoms in the interelectrode gap after the discharge has been extinguished. If Cs atoms are not replenished during the off-time to the value necessary to ignite the discharge when a positive pulse is applied to the grid, ${ }^{11,13}$ subsequent discharge ignition would not occur.

The remaining sections of this report cover a description of the device facility, the experimental procedure used to obtain the results, experimental results of the Cs-Ba tacitron switch operating in the breakdown, I-V, and current modulation modes, and finally experimental results of two Cs-Ba tacitrons operating as an inverter. 


\section{DESCRIPTION OF Cs-Ba TACITRON TEST FACILITY}

The Cs-Ba tacitron test facility at the ISNPS consists of a high-vacuum chamber and ion pump, a power rack, a control rack, PC-based data acquisition and diagnostic equipment, and the Cs-Ba tacitron device. The chamber consists of a vacuum housing with a device mounting plate and electrical feed-throughs. The diagnostic equipment consists of a CAMAC based multichannel waveform digitizer for electrical measurements and an AVD converter for temperature measurements. In addition a D/A converter is used to send test signals for calibration of the current and voltage and to locate system errors. An IBM compatible 386-PC uses a GPIB interface to control the CAMAC. The test facility is demountable, hence many different electrode materials can be tested at various $\mathrm{Cs}-\mathrm{Ba}$ vapor mixtures. The $\mathrm{Cs}$ and $\mathrm{Ba}$ reservoirs temperatures are independently contro'led to adjust the mixture vapor pressure in the gap.

The Cs-Ba tacitron device currently being tested consists of a top and a bottom triode sections and a middle diode section. Figure 1 presents a schematic cross section of the Cs-Ba tacitron. All three sections have a common, electrically grounded emitter but separate collectors. The assembled device is mounted on top of a stainless steel basis flange. The flange is heated to prevent condensation of the $\mathrm{Cs}$ and $\mathrm{Ba}$ vapor on the walls. The $\mathrm{Cs}$ and $\mathrm{Ba}$ vapors diffuse through the internal cavities in the flange before entering the interelectrode gap of the tacitron. The Cs reservoir is equipped with a long narrow orifice to minimize diffusion of $\mathrm{Ba}$ vapor and contamination of the Cs reservoir.

The emitter, grid and collector are all constructed of molybdenum. In the triode sections, the spacing between the emitter and grid is $1 \mathrm{~mm}$, and the spacing berween the emitter and collector is $4.25 \mathrm{~mm}$. The grid is $1 \mathrm{~mm}$ thick and has $0.8 \mathrm{~mm}$ holes and physical transparency of $\sim 34 \%$. The $\mathrm{Cs}$ and $\mathrm{Ba}$ vapor pressures in the gap are independently controlled by external electric heaters on their respective reservoirs. The electric heater for the emitter is a $2 \mathrm{~mm}$ diameter tungsten rod. The rod is surrounded by a tantalum tube, which returns the current from the heater to the power supply and prevents a magnetic field from developing due to the high heater current. Heating of the emitter is accomplished by thermal radiation from the tantalum tube or by electron 


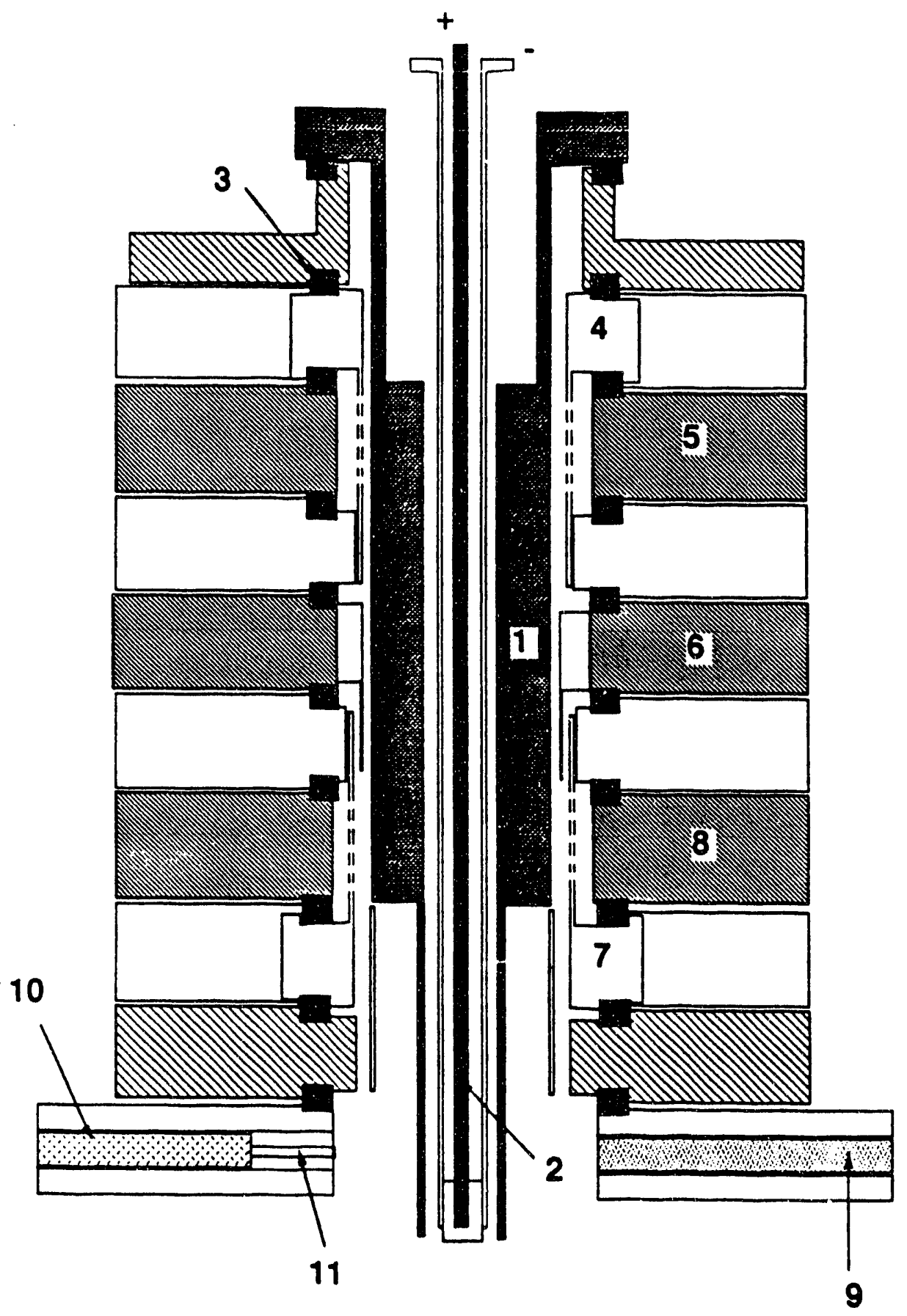

1 - Cylindrical Molybdenum Emitter, 2 - Tungsten Heater, 3 - Insulator, 4 - Grid, triode section 1, 5 - Collector, triode section 1, 6 - Collector, diode section 2, 7 - Grid, triode section 3, 8 - Collector, triode section 3, 9 - Barium reservoir connecting tube, 10 - Cesium reservoir, 11 - Throttle apperture

Figure 1. Schematic Cross-Section of the Cs-Ba Tacitron. 
bombardment, if a higher temperature is desired $(>1800 \mathrm{~K})$. The temperature of the emitter is monitored by three tungsten-rhenium thermocouples, which are located in the emitter at elevations which corresponding to the positions of the respective collector sections. The temperatures of the grid and the collector sections as well as those of the $\mathrm{Cs}$ and $\mathrm{Ba}$ reservoirs are measured using type-K thermocouples. For a more extensive description of the device, refer to El-Genk et al. ${ }^{13}$.

\section{EXPERIMENTAL PROCEDURE}

In the present experiments, measurements are always made after the $\mathrm{Cs}$ and $\mathrm{Ba}$ pressures and the temperatures of the device have reached steady-state. When the device is first turned on, a waiting period of one to two hours is required for the device to reach steady-state. Subsequently, a change of one of the operating parameters (for example, emitter temperature, Cs pressure, or $\mathrm{Ba}$ pressure) would require a much shorter waiting period, on the order of ten to fifteen minutes, for the device to reach steady-state. In I-V mode the applied voltage is increased up to $20 \mathrm{~V}$ during the first millisecond, and then it is maintained constant for the next $5 \mathrm{~ms}$. During the last millisecond the voltage is decreased to zero. To initiate discharge a constant positive voltage was applied to the grid. In the breakdown experiments, a half-sinusoidal voltage pulse is applied to the collector to determine the collector voltage when ignition occurs. In these experiments, the amplitude of the voltage pulse to the collector is kept constant at $170 \mathrm{~V}$ and the collector voltage for ignition in the breakdown mode is determined as a function of the applied positive potential to the grid, $\mathrm{V}_{\mathrm{g}+\text {. }}$

In the experiments investigating the current modulation mode of operation, the collector voltage is kept constant at $150 \mathrm{~V}$. At the selected values of the $\mathrm{Cs}$ pressure, Ba pressure and emitter temperature, the off-times for stable and unstable modulation of the tacitron are measured as functions of the applied voltage pulse to the grid for ignition. 


\section{EXPERIMENTAL RESULTS OF Cs-Ba TACITRON SWITCH}

\subsection{Establishment of Discharge Equilibrium Conditions}

Following ignition of the discharge, the time required for the concentration of heavy. components in the interelectrode gap to reach equilibrium depends on: (a) the flux of Cs ions leaving the gap, (b) the flux of Cs atoms entering the gap, and (c) the amount of Cs atoms in the gap. The latter depends on the $\mathrm{Cs}$ vapor pressure in the gap immediately before ignition and the net desorption of Cs atoms from the surfaces of the grid and collector (cold surfaces) during discharge. The initial equilibrium density of $\mathrm{Cs}$ atoms in the gap, $\mathrm{n}_{\mathrm{a} 0}$, may be derived from conditions of equality of fluxes at low Cs vapor pressure, and is given by:

$$
\mathrm{n}_{\mathrm{a} 0}=\mathrm{n}_{\mathrm{Cs}} \sqrt{\frac{\mathrm{T}_{\mathrm{Cs}}}{\mathrm{T}_{\mathrm{gap}}}}
$$

where $\mathrm{T}_{\mathrm{Cs}}$ is the cesium reservoir temperature. The cesium vapor density at the reservoir, $\mathrm{n}_{\mathrm{Cs}}$, and the average temperature in the interelectrode gap, $T_{\text {gap }}$, are respectively given by:

$$
\mathrm{n}_{\mathrm{Cs}}=\frac{133 \mathrm{P}_{\mathrm{Cs}}}{\mathrm{kT} \mathrm{Cs}} \text { and } \mathrm{T}_{\text {gap }}=\frac{\mathrm{T}_{\mathrm{E}}+\mathrm{T}_{\mathrm{C}}}{2} \text {, }
$$

where $P_{C s}$ is the cesium vapor pressure in the reservoir, $k$ is Boltzmann's constant, $T_{E}$ is the emitter temperature, and $T_{C}$ is the collector temperature. Also, the flux of $C s$ atoms entering the gap from the surrounding, $\Gamma_{\mathrm{a} 0}$, is given by:

$$
\Gamma_{\mathrm{a} 0}=\frac{1}{4} \mathrm{n}_{\mathrm{a} 0} \overline{\mathrm{v}_{\mathrm{a}}}=\frac{1}{4} \mathrm{n}_{\mathrm{Cs}} \sqrt{\frac{\mathrm{T}_{\mathrm{Cs}}}{\mathrm{T}_{\mathrm{gap}}}} \sqrt{\frac{8 \mathrm{kT} \mathrm{T}_{\mathrm{gap}}}{\pi \mathrm{M}_{\mathrm{a}}}}=\frac{1}{4} \mathrm{n}_{\mathrm{Cs}} \sqrt{\frac{8 \mathrm{kT} \mathrm{T}_{\mathrm{Cs}}}{\pi \mathrm{M}_{\mathrm{a}}}}
$$

where $\overline{\mathrm{a}}$ and $\mathrm{M}_{\mathrm{a}}$ are the thermal velocity and mass of the Cs atoms, respectively. 
During discharge, the $\mathrm{Cs}$ atom flux from the surrounding into the discharge region remains the same as when the discharge is absent (Eq. 3); however, the ion flux from the discharge region to the surrounding, $\Gamma_{\mathrm{j}}$. can be expressed as:

$$
\Gamma_{\mathrm{i}}=0.61 \mathrm{n}_{\mathrm{i}} \sqrt{\frac{k T_{e}}{\mathrm{M}_{\mathrm{i}}}},
$$

where $n_{i}$ is the Cs ion density, $T_{e}$ is the electron temperature, and $M_{i}$ is the mass of the cesium ion. At equilibrium conditions for a highly ionized plasma the fluxes in Eqs. (3) and (4) are equal. Through the use of this equality, the equilibrium ion density in the discharge volume, $\mathrm{n}_{\mathrm{j}}^{\text {eq, }}$, can be calculated as follows:

$$
n_{i}^{e q}=\frac{0.654 P_{C s}}{\sqrt{T_{g a p} T_{e}}}
$$

The ion density in the gap at any time during discharge can also be determined from the measured ion current, $\mathrm{I}_{\mathrm{i}}$, to the grid when a shor negative pulse is applied to the grid as:

$$
n_{i}=\frac{1.64 \times 10^{-2} I_{i}}{q A_{g}} \sqrt{\frac{M_{i}}{k T_{e}}}
$$

where $q$ is the electron charge and $A_{g}$ is the surface area of the grid. In this mode, the grid serves as a probe for determining the plasma conditions in the gap.

The time for reaching equilibrium conditions during discharge, $\tau_{\text {eq }}$, depends on the fluxes in Eqs. (3) and (4) and on the total amount of Cs atoms leaving the gap during the discharge, $\Delta \mathrm{N}_{\mathrm{a}}$. This time can be represented as:

$$
\tau_{e q}=\frac{\Delta N_{a}}{\left(\Gamma_{i}^{m}-\Gamma_{a 0}\right) S} .
$$

where $\Gamma_{i} \mathrm{~m}$ is the mean ion flux leaving the discharge region and $\mathrm{S}$ is the cross-sectional area between the emitter and grid through which the ions leave the discharge region. 
The time dependent discharge currents and forward conduction voltage are shown in Fig. 2. The negative voltage pulses to the grid are utilized to probe the plasma and measure the ion current in the discharge gap, $\mathrm{I}_{\mathrm{i}}$, which is used to determine the mean plasma concentration in the discharge volume. The voltage pulses to the grid are applied continuously during the entire measurement time $(\sim 20 \mathrm{~ms})$, although the pulses are plotted only during the first $2 \mathrm{~ms}$ in order to view the ion current. The clipped or constant portion of the grid ion current at the beginning of operation $(\tau=0)$ is due to the limitation of the current by the grid pulse generator. The fact that the grid voltage during the constant portion of the grid current is almost zero, suggests that the ion current is being limited by the circuit. Assuming an electron temperature, $\mathrm{T}_{\mathrm{e}}=1.5 \times 10^{4} \mathrm{~K}$, the equilibrium ion density obtained from Eq. (5) is $n_{i}=2.2 \times 10^{13} \mathrm{~cm}^{-3}$. As shown in Fig. 2, the measured ion current to th grid at the time of reaching equilibrium is about $3 \mathrm{~A}$, for which $\mathrm{n}_{\mathrm{i}}=$ $2.45 \times 10^{13} \mathrm{~cm}^{-3}$ according to Eq. (6). This value of the ion current should have been close to equilibrium as indicated by the very slow increase in the grid ion current with time (see Fig. 1). Indeed, the ion concentration calculated from the measured ion current to the grid at the time of extinguishing $\left(2.45 \times 10^{13} \mathrm{~cm}^{-3}\right)$ is very close to that calculated above assuming equilibrium and a highly ionized plasma in the interelectrode gap. However, this concentration is more than 3 times lower than that of the Cs atom density in the gap $\left(10^{14} \mathrm{~cm}^{-3}\right)$, before discharge is ignited, at the initial Cs pressure of $10^{-2}$ torr. As shown in Fig. 2 the initial ion current at ignition is about $12 \mathrm{~A}$, which corresponds to an ion density of $9.8 \times 10^{13} \mathrm{~cm}^{-3}$ using Eq. (6). This value coincides with the initial Cs atom density of $10^{14} \mathrm{~cm}^{-3}$, suggesting that the plasma becomes highly ionized very quickly.

It is also possible from the measured ion current to the grid to calculate the approximate time to reach equilibrium during discharge. In Fig. 2, $I_{C}, I_{g}, V_{C E}$, and $V_{g}$ are the collector discharge current, grid current, applied collector voltage, and applied grid voltage, respectively. As shown in Fig. 2, after the discharge is ignited, the ion flux to the grid decreases gradually with time. As Fig. 2 shows, while the ion current at the time of reaching equilibrium in the discharge is about $3 \mathrm{~A}$, which corresponds to an ion flux of $1.44 \times 10^{18} \mathrm{ion} / \mathrm{cm}^{2} \mathrm{~s}$, it could have been as much as 


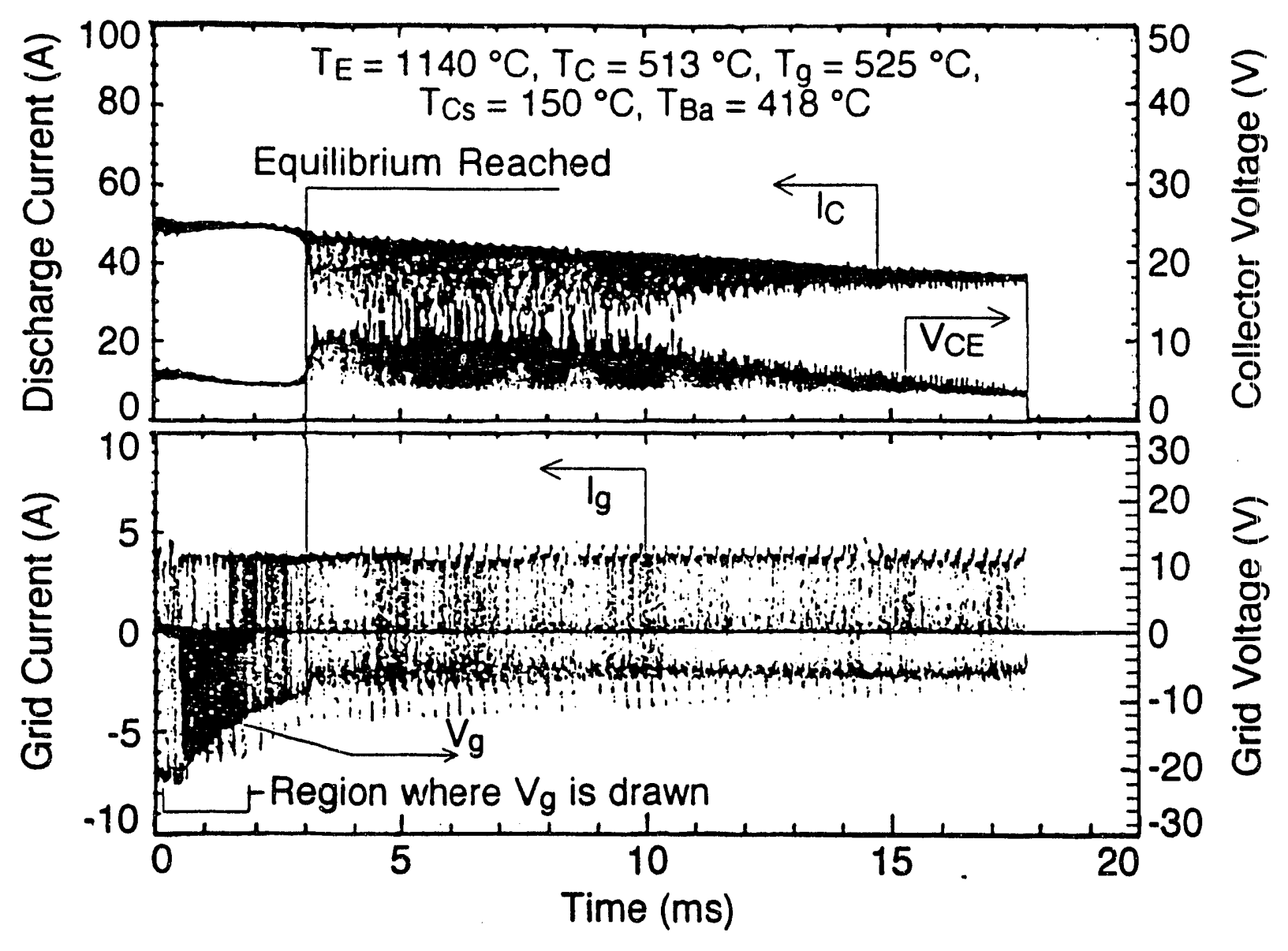

Figure 2. Discharge Current, Forward Voltage Drop and Ion Current to the Grid Illustrating the Time to Reach Equilibrium During the Discharge. 
$12 \mathrm{~A}$ at the time of ignition, which corresponds to an ion flux of $5.77 \times 10^{18} \mathrm{ions} / \mathrm{cm}^{2} \mathrm{~s}$. These values give a mean ion flux during discharge, $\Gamma_{\mathrm{i}}^{\mathrm{m}}=3.51 \times 10^{18} \mathrm{ions} / \mathrm{cm}^{2} \mathrm{~s}$. Because this value is much higher than the Cs atom flux from the surrounding region into the gap, the average rate at which the heavy components in the gap decrease during the discharge period or on-time, $\tau_{\text {on, }}$, is equal to $\left(\Gamma_{\mathrm{i}}^{\mathrm{m}}-\Gamma_{\mathrm{a} 0}\right)$; this is on the order of $2.26 \times 10^{18}$ particles $/ \mathrm{cm}^{2} \mathrm{~s}$. Assuming that $\Delta \mathrm{N}_{\mathrm{a}}$ in $\mathrm{Eq}$. (7) is the difference between the amount of heavy components in the volume of the gap before discharge ignition, $\mathrm{n}_{\mathrm{a} 0}$, and during discharge after equilibrium is established, $\mathrm{n}_{\mathrm{i}}$ eq, yields:

$$
\Delta \mathrm{N}_{\mathrm{a}}=\left(\mathrm{n}_{\mathbf{a} 0}-\mathrm{n}_{\mathrm{i}}^{\mathrm{eq}}\right) \mathrm{V}_{\mathrm{gap}} \sim\left(10^{14}-2.45 \times 10^{13} \mathrm{~cm}^{-3}\right) 1.5 \mathrm{~cm}^{3}=1.16 \times 10^{14} \text { atoms }
$$

where $V_{\text {gap }}$ is the volume of the discharge regıon between the emitter and grid. Substituting this value of $\Delta \mathrm{N}_{\mathrm{a}}$ into (7) yields a characteristic time $\tau_{\mathrm{eq}}=100 \mu \mathrm{s}$. As indicated in Fig. 2 and also in Fig. 3, this time is an order of magnitude lower than measured $(-2-3 \mathrm{~ms})$. Figure 3 shows the tacitron operating in the breakdown mode. Therefore, the amount of atoms in the gap, immediately following discharge ignition, must have been significantly greater. The additional Cs atoms in the gap could have been provided by the desorption of Cs atoms from the electrode surfaces during discharge.

For a monolayer coating, the surface concentration of $\mathrm{Cs}$ atoms is about $2 \times 10^{14}$ atoms $/ \mathrm{cm}^{2}$. Assuming no $\mathrm{Cs}$ atoms are present on the hot emitter surface, because of its low adsorption capability to $\mathrm{Cs}$ in the presence of a barium film, and that the concentration of Cs atoms on the comparatively colder surfaces of the collector and grid decreases proportional to the heavy component density reduction in the gap during discharge, then:

$$
\Delta \mathrm{N}_{\mathrm{a}} \sim\left(10^{14}-2.45 \times 10^{13} \mathrm{atoms} / \mathrm{cm}^{3}\right) 1.5 \mathrm{~cm}^{3}+\left(19 \mathrm{~cm}^{2} \times 1.25 \times 10^{14} \text { atoms } / \mathrm{cm}^{2}\right)=2.5 \times 10^{15} \text { atoms }
$$




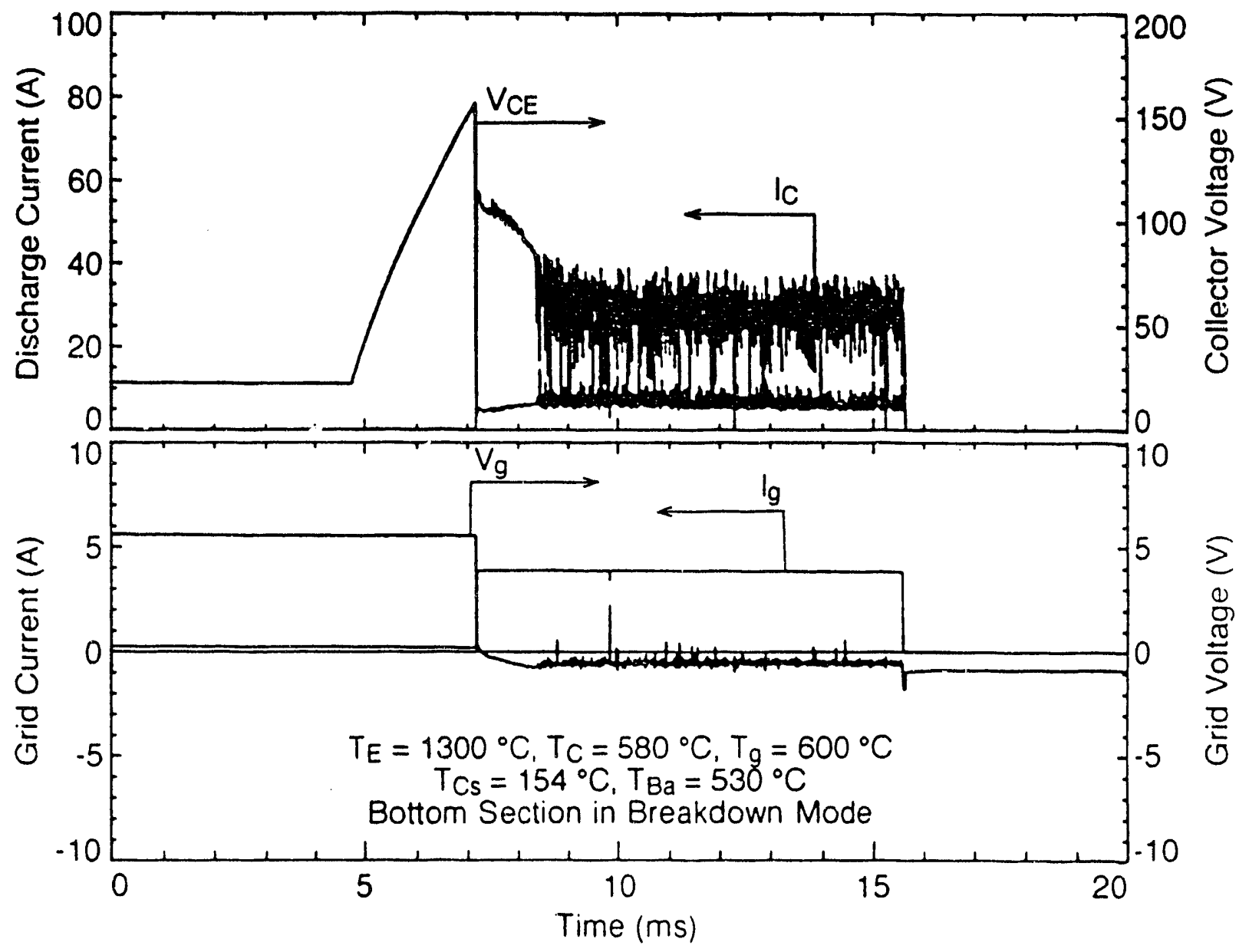

Figure 3. Measured Signals Illustrating the Conditions of the $\mathrm{Cs}-\mathrm{Ba}$ Tacitron During the Breakdown Mode of Operation. 
In Eq. (9) the first term accounts for the net change in the heavy components in the discharge volume, in the absence of $\mathrm{Cs}$ desorption, and the second term represents the contribution due to desorption of $\mathrm{Cs}$ atoms from the surface of the grid and collector during discharge. Substituting this value of $\Delta \mathrm{N}_{\mathrm{a}}$ in Eq. (7) increases the time to reach equilibrium during discharge, $\tau_{\text {eq }}$, to $\sim 2$ ms, which is very close to the measured time of $2-3 \mathrm{~ms}$ in Figs. 2 and 3. Therefore, it is concluded that the source of Cs atoms in the gap, immediately following the initial ignition of the discharge $(\tau=0)$, is not only the volume of the gap but also the desorption from the grid and collector surfaces.

\subsection{Voltage Drop Influence on the Equilibrium Conditions}

The forward conduction voltage drop is an important parameter to future applications of the tacitron because it dictates the switching efficiency of the device and the range of input voltages that the device could be beneficial for. The switching efficiency, $\eta$, is defined herein as the ratio of the difference between the applied open circuit voltage and the forward conduction voltage drop, ( $V_{C E}$ - $\left.V_{d}\right)$ to the applied open circuit voltage, $V_{C E}$, where $V d$ is the voltage drop between the collector and emitter. In order to maintain a switching efficiency $>90 \%$ for DC power systems having an output voltage as low as $50 \mathrm{~V}$, the maximum voltage drop in the device should not exceed 4-5 V. Results to date show that at a given discharge current, the voltage drop in the triode sections decreases with increasing the Cs pressure in the gap and the emission current. Because the Cs vapor pressure in the gap during current modulation is less than in the first moment of discharge ignition, the voltage drop, in the I-V mode, at the same discharge current, will be somewhat lower than that during current modulation at the same initial Cs pressure at the moment of the discharge. Therefore, it is interesting to analyze the change in the voltage drop with time during discharge ignition, I-V mode, as a function of emission conditions (emitter temperature, $\mathrm{T}_{\mathrm{E}}$, and barium reservoir temperature, $\mathrm{T}_{\mathrm{Ba}}$ ) and $\mathrm{Cs}$ pressure (a function of $\mathrm{T}_{\mathrm{Cs}}$ ).

The changes in the discharge current and voltage drop with time after ignition in the $\mathrm{I}-\mathrm{V}$ mode are shown in Figs. 4(a)-(e), 5(a)-(e), and 6(a)-(e), for different emitter temperatures and Bis 


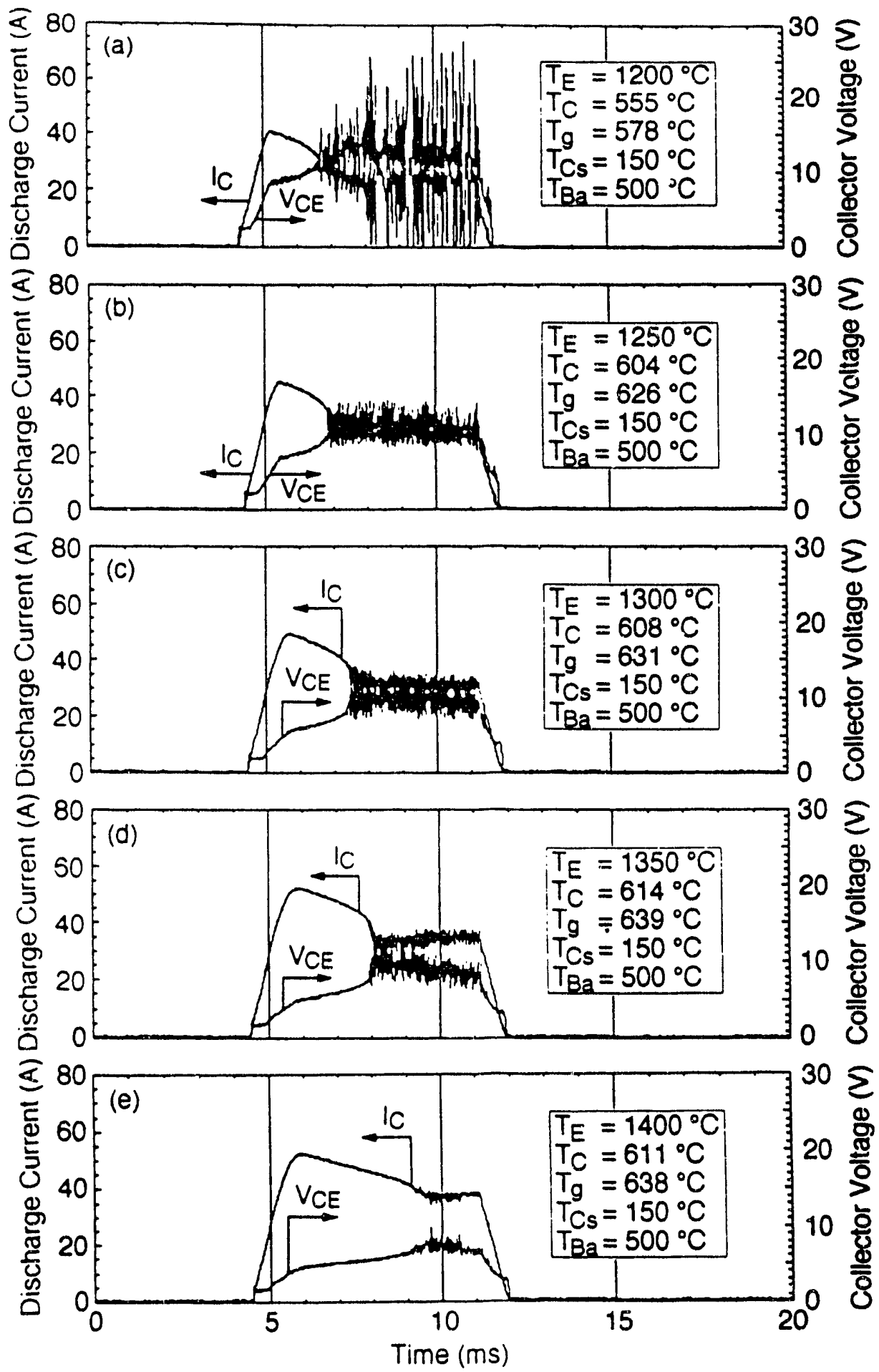

Figure 4. Effect of Increasing Emitter Temperature on Discharge Current and Forward Voltage Drop in the I-V Mode. 


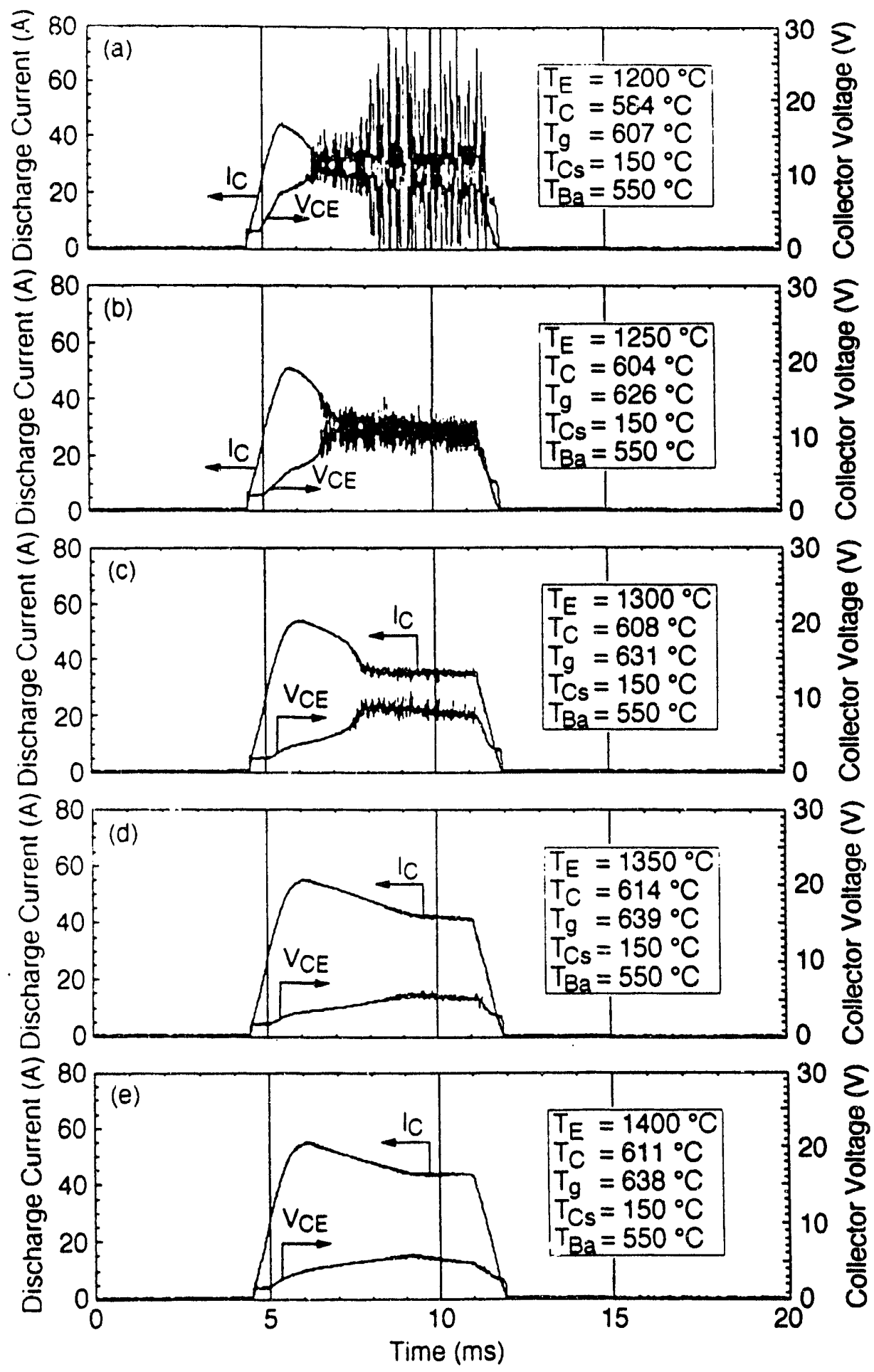

Figure 5. Effect of Increasing Barium Pressure on Discharge Current and Forward Voltage Drop in the I-V Mode. 


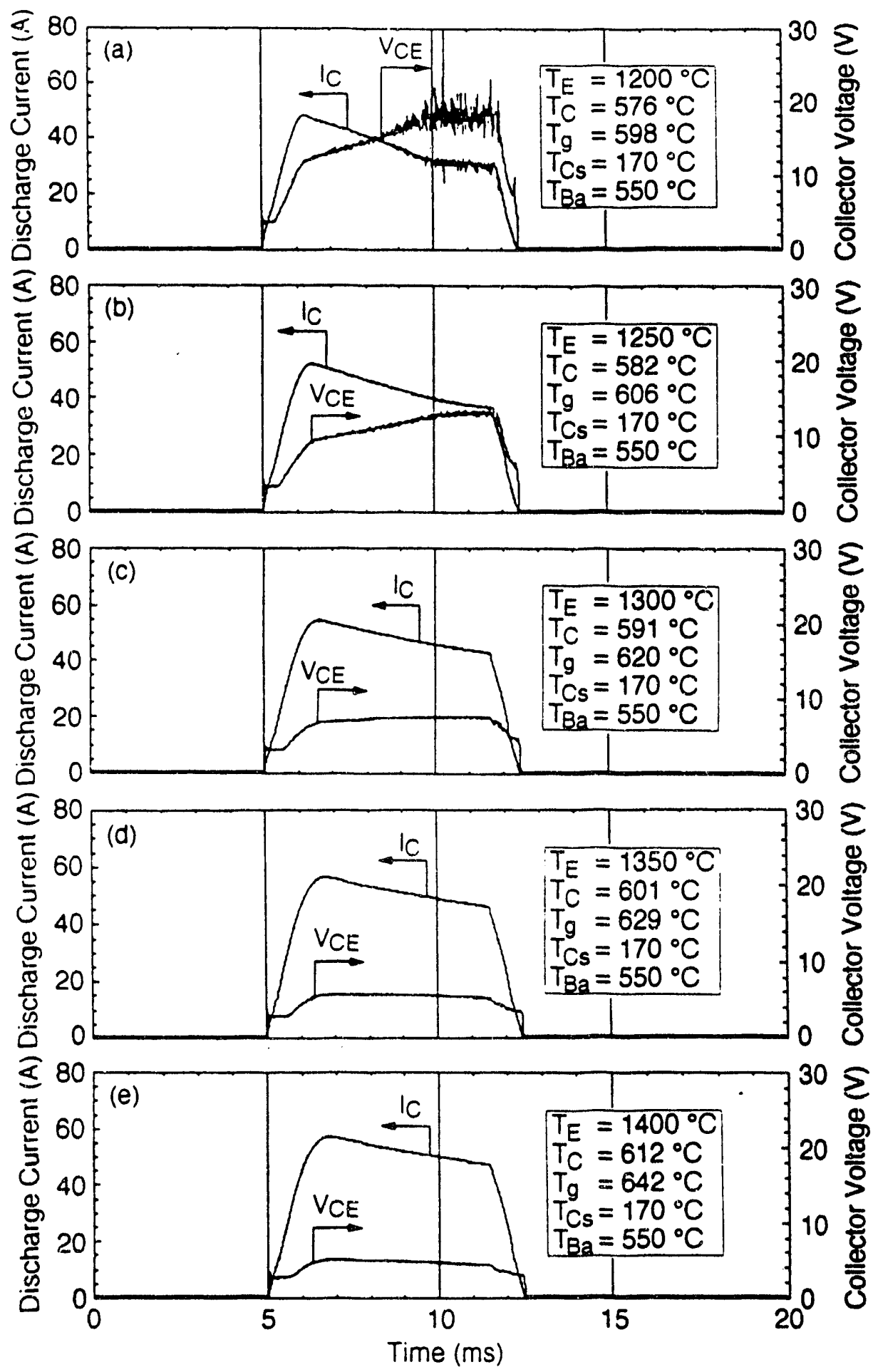

Figure 6. Effect of Increasing Cesium Pressure on Discharge Current and Forward Voltage Drop in the I-V Mode. 
and Cs vapor pressures. In Figs. 4-6 the changes in the discharge current and voltage drop during the $5 \mathrm{~ms}$ period (starting at $6 \mathrm{~ms}$ on the time scale), when the source voltage is constant, is due to the decreasing Cs vapor pressure as a result of heavy components leaving the gap (i.e. ion current). As it is shown from the figures, the current rises initially at a practically constant voltage drop. At the end of the constant voltage drop region, at the point where the voltage drop begins to increase, the discharge current is practically equal to the emission current from the emitter. From the figures it is seen that this emission current increases with rising emitter temperature and/or Ba pressure. Further increase in the discharge current, causes the voltage drop to rise in order to increase the emission current partially by Schottky effect and partially by the increased ion current to the emitter. After the discharge current reaches its maximum value, $i$ i begins to decrease in spite of the increase in voltage drop. Such increase in the voltage drop occurs as a result of the decrease in the voltage drop on the external load as the discharge current decreases. The duration of decreasing discharge current, at the end of which equilibrium occurs, is related to non-stationary processes associated with heavy components leaving the discharge gap. As indicated earlier, such equilibrium is characterized by the equality of ion flux from the gap and the Cs atom flux into the gap. Results in Fig. 4 show that increasing the emission current, by increasing the emitter temperature, not only reduces the voltage drop, but also increases the discharge duration for reaching equilibrium (see Figs. (4a) and (4e)). For example, increasing the emitter temperature from $1200{ }^{\circ} \mathrm{C}$ to $1400{ }^{\circ} \mathrm{C}$ causes the voltage drop to decrease from $-3.5 \mathrm{~V}$ to $2.5 \mathrm{~V}$ and the duration for reaching equilibrium to increase from $3 \mathrm{~ms}$ to $4.5 \mathrm{~ms}$. Figures 4-6 also show that increasing the $\mathrm{Cs}$ vapor pressure increases the discharge time before equilibrium conditions in the gap are established and lowers the corresponding voltage drop in the discharge region.

Low voltage drop is indicative of lower energy dissipation in the plasma and therefore, lower electron temperature, resulting in a lower ion flux from the gap (Eq. 4). This lower ion flux from the gap, increases the duration for establishing equilibrium (Eq. 7). In addition, increasing the Cs pressure, increases the amount of Cs atoms into the gap from the surrounding regions, hence increasing the time to reach equilibrium in the gap. This effect is shown well in Figs. 4-6. 
The comparison of discharge current and corresponding voltage drop as a function of time at different emission conditions ( $\mathrm{T}_{\mathrm{E}}$ and/or $\mathrm{T}_{\mathrm{Ba}}$ ) testifies to the significant role the electron temperature has on the amount of heavy components leaving the gap during discharge. At a given Cs pressure (or $\mathrm{T}_{\mathrm{Cs}}$ ), the lower the emission and therefore discharge current, the larger the voltage drop and hence, the electron temperature, which affects the heavy component density in the gap, (refer to Eq. (5)). As Eq. (5) indicates, the heavy component density in the gap at equilibrium decreases as the electron temperature increases and/or the Cs vapor pressure decreases. The current and voltage oscillations in Figs. 4-6 at low emission (low emitter temperature and/or low Ba pressure) is indicative of the low heavy component density in the gap at high electron temperatures. When the Cs vapor pressure in the surrounding space is increased, according to Eq. (5), the equilibrium ion density in the gap increases, causing the plasma oscillations in the discharge region to disappear (see Figs. 5(e) and 6).

It is important to recognize that for a given grid geometry, stable current modulation is possible at definite combinations of the discharge current and Cs vapor pressure. In order to receive the lowest voltage drop, the discharge current, which can be controlled by the external load should be kept below the emission current; this is the region in Figs. 4-6 where the voltage drop is independent of the discharge current. The appropriate Cs vapor pressure is that resulting in highly ionized plasma in the discharge region at a given discharge current. For example, it is possible to reduce the voltage drop in the tacitron during stable current modulation from $6-8 \mathrm{~V}$ to $3-3.5 \mathrm{~V}$ by fulfilling the aforementioned two conditions, namely: (a) operating at a discharge current that is lower than the emission current, and (b) maintaining a Cs pressure that is high enough for ignition to occur when a positive pulse is applied to the grid but low enough to induce close to a fully ionized plasma in the discharge region so that when a negative pulse is applied to the grid, the discharge will extinguish. While the first condition reduces the voltage drop during discharge, the second condition should be fulfilled in order to maintain stable current modulation. 


\subsection{Ignition in the Breakdown Mode}

Experiments are performed to measure the effects of the emitter temperature and collector potential on the grid potential required for ignition in the breakdown mode. Figure 3 presents a typical response of the Cs-Ba tacitron operating in the breakdown mode. By varying the positive grid potential, $\mathrm{V}_{g+}$, breakdown curves are generated and shown in Fig. 7. In this figure the grid voltage for ignition is plotted versus the $P_{\text {gap }} d$ parameter, where $d$ is the distance between the emitter and grid $(1 \mathrm{~mm})$, and $\mathrm{P}_{\text {gap }}$ is the $C$ s pressure in the discharge gap (in torr). The gap between the emitter and grid is used for the $P_{\text {gap }} d$ parameter in Fig. 7, since it has been demonstrated that the discharge initially ignites in the emitter-grid region ${ }^{11}$. This figure demonstrates that the collector voltage insignificantly affects the grid potential for ignition, while the effects of the emitter temperature are small. It is worth noting that at $P_{\text {gap }} d$ values higher than $0.025 \mathrm{~mm}$-torr, the grid potential for ignition becomes almost independent of $\mathrm{P}_{\text {gap }} \mathrm{d}$ and very close to the Cs ionization potential $(3.89 \mathrm{eV})$.

\subsection{Stable and Unstable Current Modulation Regimes}

Before discussing the extinguishing characteristics of the tacitron, it is important to define the nomenclature associated with the different processes during current modulation. A typical timing diagram for stable modulation of the device is shown in Fig. 8. The upper part of the figure describes the collector voltage and current characteristics and the lower part of the figure describes the grid voltage and current characteristics. Stable current modulation in the Cs-Ba tacitron occurs when the modulation frequency of the tacitron, $f_{m}=1 / \tau_{m}$, equals the applied modulation frequency to the grid, $\mathrm{f}_{\mathrm{g}}=1 / \tau_{\mathrm{g}}$. Under this condition, the operating conditions (Cs pressure and discharge current) are such that discharge ignition and extinguishing occur when positive and negative pulses are applied to the grid, respectively. Failure to ignite and/or to extinguish the discharge results in unstable current modulation, causing $f_{m}$ to be less than $f_{g}$.

Typical extinguishing and ignition characteristics at a frequency of about $5 \mathrm{kHz}$ are shown in Fig. 8, the operating conditions are listed in the figure caption. The five regions of interest in 


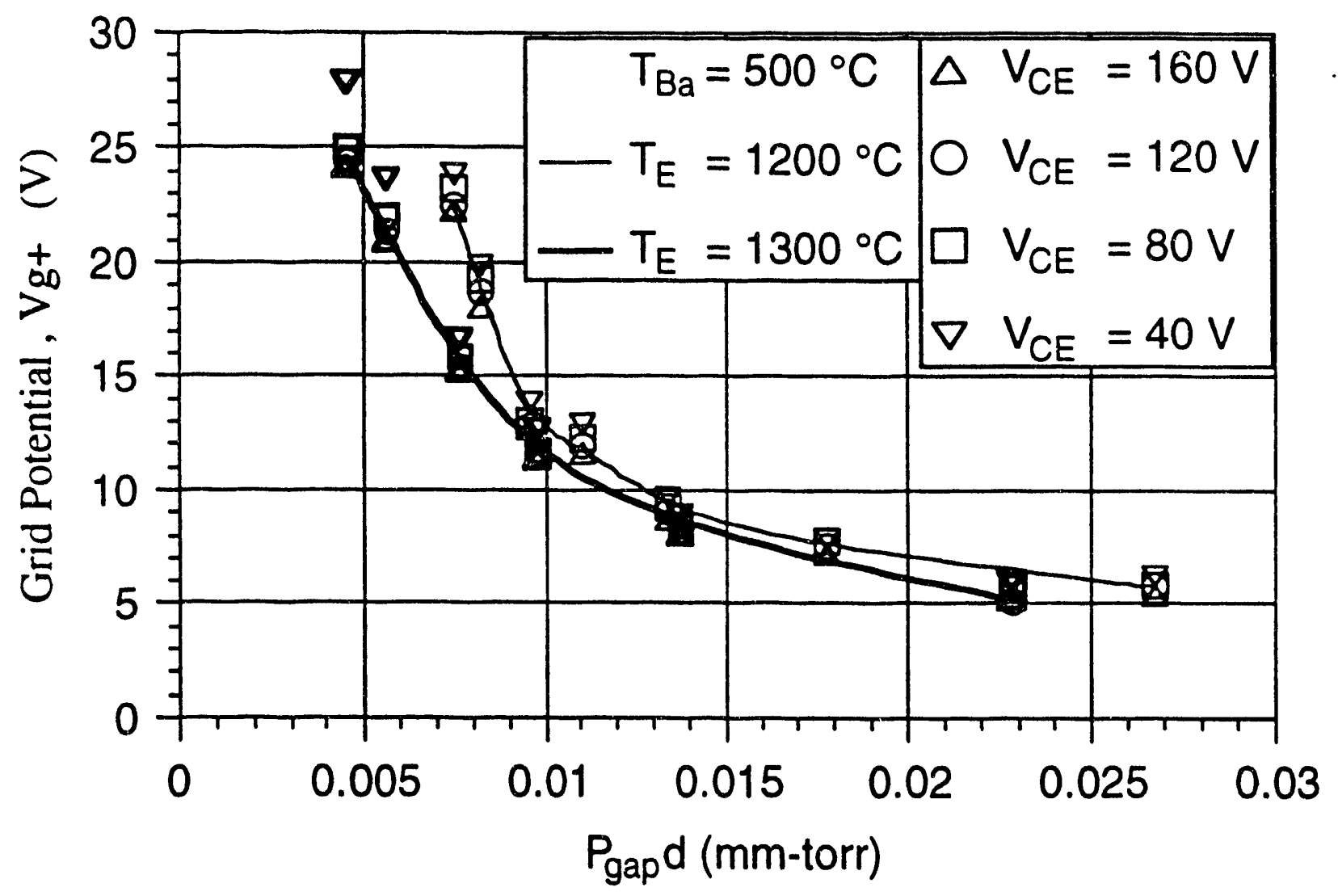

Figure 7. Effect of Emitter Temperature on the Grid Potential for Ignition in the Breakdown Mode. 

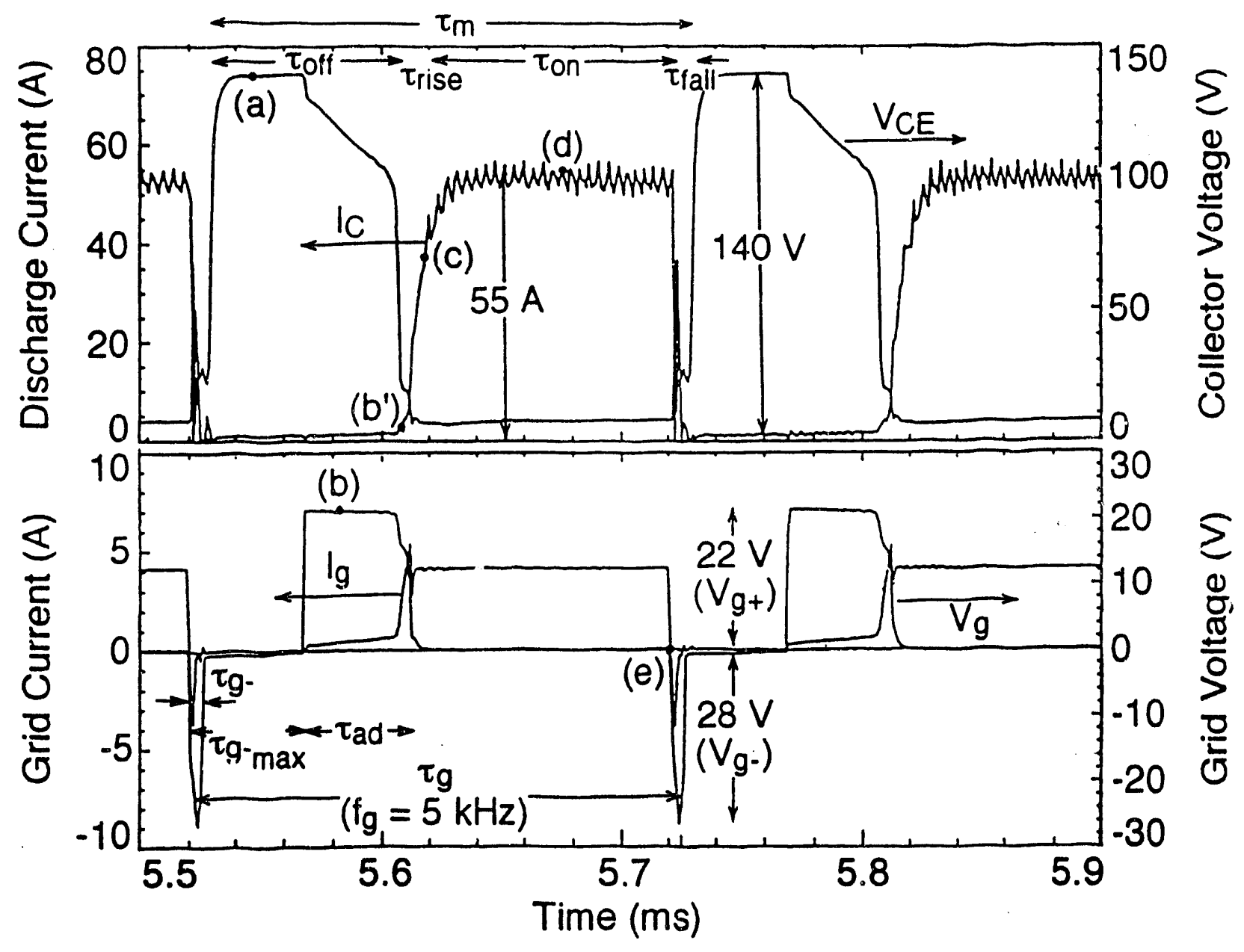

Figure 8. Typical Extinguishing and Ignition Characteristics During Stable Current Modulation at $5 \mathrm{kHz}\left(\mathrm{T}_{\mathrm{E}}=1233^{\circ} \mathrm{C}, \mathrm{T}_{\mathrm{C}}=583^{\circ} \mathrm{C}, \mathrm{T}_{\mathrm{g}}=585^{\circ} \mathrm{C}, \mathrm{T}_{\mathrm{Cs}}=151^{\circ} \mathrm{C}\right.$, and $\left.\mathrm{T}_{\mathrm{Ba}}=530^{\circ} \mathrm{C}\right)$. 
Fig. 8 are labeled as: (a) off-state, (b) positive grid potential for ignition, (c) ignition of discharge, (d) on-state, and (e) negative grid potential for extinguishing. The non-square shape of the collector potential (see Fig. 8) is due to a $100 \Omega$ resistor at the output of the collector voltage supply. This resistor is installed in order to determine the value of the collector current during the off-state from the measured voltage drop across the resistor. At $40 \mu \mathrm{s}$ after applying the positive grid potential, a discharge develops between the emitter and grid. This time is known as the anode-delay, $\tau_{\mathrm{ad}}$, which is the time necessary for the ignition of the discharge after the application of the positive grid potential. Shortly thereafter the main discharge ignites, point (b'), causing the collector and grid currents ( $\mathrm{I}_{\mathrm{C}}$ and $\mathrm{I}_{\mathrm{g}}$ ) to increase, collector potential to decrease (voltage drop in the gap), and grid potential to drop to almost zero. As demonstrated in Fig. 8, full discharge is achieved after a $15 \mu$ s rise-time $\left(\tau_{\text {rise }}\right)$, point $(c)$. Full discharge, point $(d)$, remains on until a negative potential, $\mathrm{V}_{g_{-}}=28 \mathrm{~V}$, is applied to the grid for a time duration of $\tau_{g_{-}}=5 \mu \mathrm{s}$, point (e). At this point, the induced instabilities interrupt the discharge. The maximum value of the time duration of the negative grid potential for this device is $50 \mathrm{~ms}$ ( $\left.\tau_{g-\max }\right)$. Eventually, the discharge is extinguished after a $5 \mu$ s fall-time ( $\tau_{\text {fall }}$ ), resulting in $\mathrm{I}_{\mathrm{C}}=0, \mathrm{~V}_{\mathrm{CE}}=140 \mathrm{~V}$ and $\mathrm{I}_{\mathrm{g}}$ going to zero.

Although operating at a switching frequency of $5 \mathrm{kHz}$ for a single triode is shown to be possible (see Fig. 8), the plasma behavior in the tacitron is not well understood. Sometimes, the main discharge is not ignited after applying a positive potential to the grid nor extinguished when a negative potential is applied to the grid (unstable modulation). Representative results of stable and unstable moduiation are shown in Figs. 9a and 9b. In Fig. 9a, because the time after extinguishing (off-time, $\tau_{\text {off }}$ ) is not long enough to replenish the Cs atoms, ignition does not occur when the positive grid voltage pulse is applied, but ignites when a second pulse is applied at a later time, point (a). After the second time the discharge is extinguished successfully, point (b), the discharge ignites at the end of the positive grid pulse, point (c). Shortly thereafter, a negative potential is applied to the grid, but because the discharge has not been on long enough to reduce the amount of heavy components (mostly ions) in the discharge volume, the discharge did not extinguish. It is also seen in Fig. 9b, that when the on-time is not long enough, the discharge fails to extinguish. 

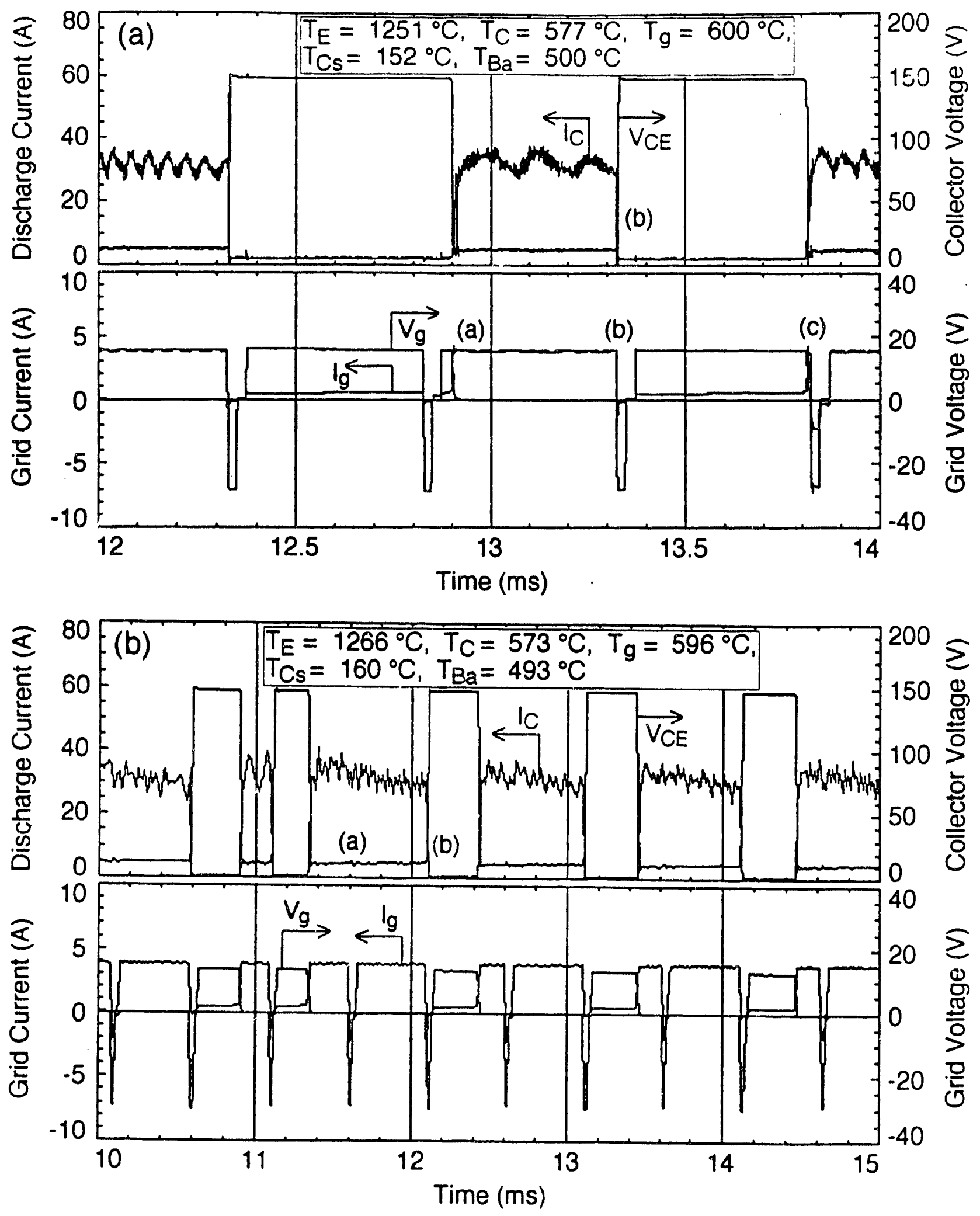

Figure 9. Typical Extinguishing and Ignition Characteristics During Unstable Current Modulation; (a) Failure to Ignite, (b) Failure to Extinguish. 
point (a), but is extinguished when a second negative pulse is applied 2-4 ms later, point (b). Figure $9 \mathrm{~b}$ also shows that there is always a delay time for ignition to occur after applying a positive pulse to the grid, $\tau_{\mathrm{ad}}$.

Although, the geometry of the grid in the present device is far from optimal with respect to current modulation and voltage drop in the device during discharge, the diameter of the grid holes of $0.8 \mathrm{~mm}$ is chosen to investigate the tacitron working regimes under conditions of abrupt extinguishing. When mostly ion current exists after the application of a negative pulse to the grid the dimension of the Langmuir layer, calculated from " $3 / 2$ law" under typical conditions of current modulation, is on the order of $10^{-3}$ to $2 \times 10^{-3} \mathrm{~cm}$. (The Debye length calculated from the mean plasma concentration determined from the ion current to the grid at the moment of extinguishing, assuming typical electron temperatures of $10^{4}-1.5 \times 10^{4} \mathrm{~K}$, is on the same order). Because the dimension of the volume discharge region for interruption by Langmuir shielding is about two orders of magnitude smaller than the diameter of the grid apertures, it can not be the mechanism for quenching the discharge in the Cs-Ba tacitron. As indicated earlier, the mechanism for extinguishing the discharge in the Cs-Ba tacitron is basically the loss of heavy components from the discharge volume during conduction.

It is seen from the previous examples (Fig. 9) that in order to maintain stable modulation the discharge should be kept on for a definite time (on-time, $\tau_{\text {on }}$ ) in order to successfully extinguish by a negative pulse to the grid. Also, ignition occurs only with a definite delay time after applying the positive pulse on the grid $\left(\tau_{\mathrm{ad}}\right)$. The on-time to extinguishing depends on the discharge current, $I_{C}$, electron temperature, $T_{e}$, and $C s$ vapor pressure, while $\tau_{a d}$ depends on the rate of decrease in the heavy component density in the gap during discharge, the magnitude of the positive voltage pulse to the grid and the Cs vapor pressure. The Cs pressure in the gap decreases after ignition due to loss of heavy components into the surrounding regions, and is restored after extinguishing due to the diffusion of $\mathrm{Cs}$ atoms from the surrounding regions. Therefore, the Cs vapor pressure in the discharge gap oscillates between two definite values at a frequency coinciding 


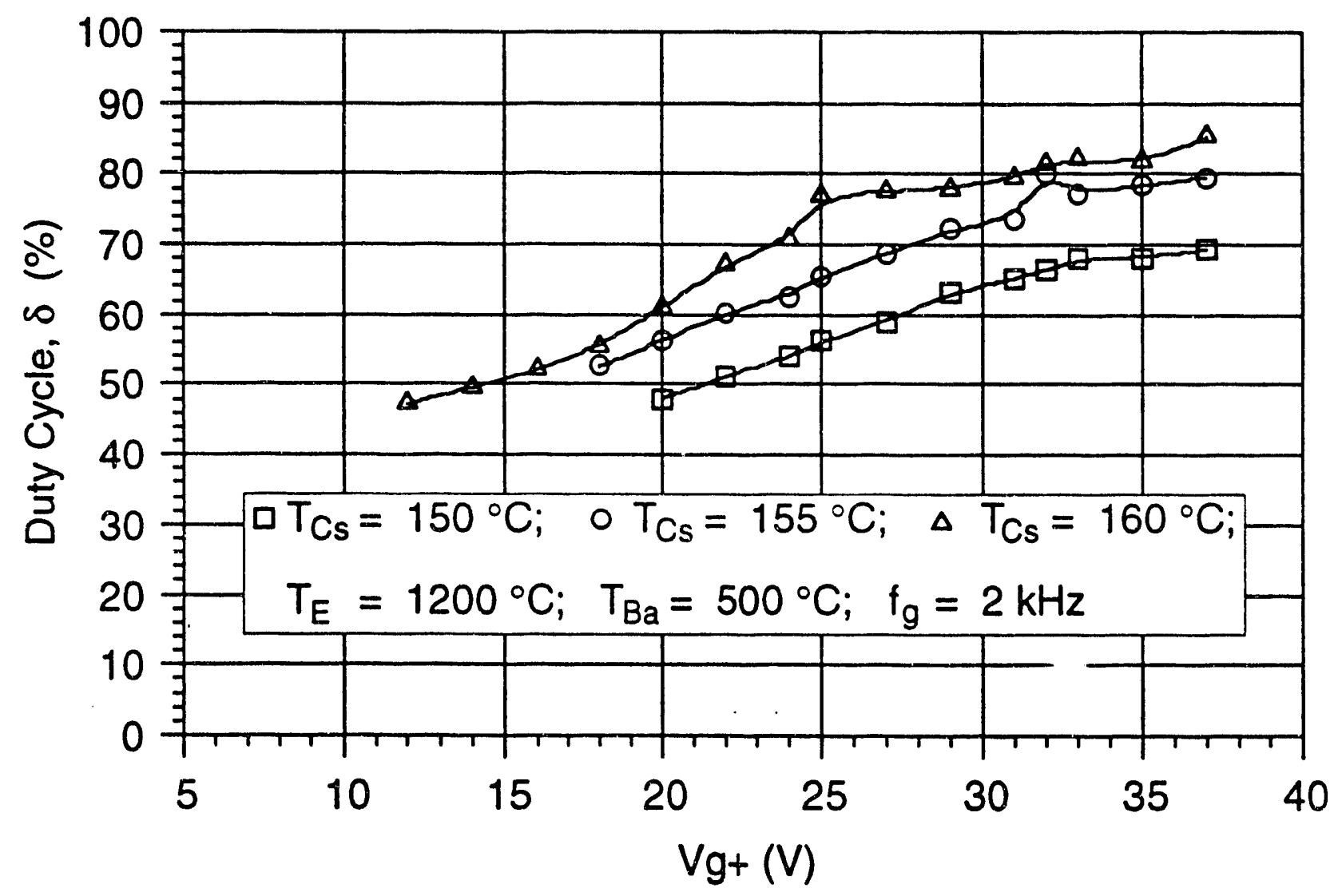

Figure 10. Effect of Ignition Grid Potential on Duty Cycle. 
with the modulation frequency. Extinguishing and ignition are possible when these definite values of the Cs pressure are reached.

The relationship between the on-time and off-time for stable modulation can be expressed in terms of the duty cycle, $\delta$. Figure 10 shows the duty cycle during stable modulation as a function of the applied positive grid voltage, $\mathrm{V}_{\mathrm{g}+}$. Data in Fig. 10 are measured at an applied grid modulation frequency of $2 \mathrm{kHz}$ and a discharge current of $\sim 45 \mathrm{~A}$. This figure shows that increasing either the grid voltage for ignition or the initial Cs pressure decreases the delay-time, $\tau_{\mathrm{ad}}$, increasing both the discharge time and the duty cycle. These results are slightly different at other modulation frequencies and discharge currents, but the general trend is that stable modulation for most regimes is seen at $\delta 550 \%$. This similarity in behavior might be connected with equal variations in the values of the Cs vapor pressure in the gap corresponding to discharge ignition and extinguishing, respectively.

\subsection{Discharge Ignition During Current Modulation}

During stable current modulation because the Cs atom concentration in the gap at the moment of applying the ignition pulse to the grid is lower than that necessary for breakdown, ignition of the discharge is only possible after a certain delay time (see Fig. 8). This anode delaytime is needed to replenish the Cs atom density in the gap. In Fig. 8, the operation in the modulation regime lowers the $\mathrm{Cs}$ atom concentration in the gap to the point where a positive grid voltage as high as $22 \mathrm{~V}$ would not cause instantaneous breakdown. When a high voltage pulse of $22 \mathrm{~V}$ is applied to the grid, small currents can be seen at the collector and the grid, which is an indication of ionization strengthening. Since the flux of Cs atoms entering the gap is controlled by the temperature of the cesium reservoir (Eq. (3)), it does not change whether the discharge is on or off. However as discussed earlier the heavy particle density in the interelectrode gap drops during discharge due to ion leakage from the gap to the surrounding region. 11 Therefore, after the discharge is extinguished, the Cs atom density in the gap must recover, by diffusion of Cs atoms from the surrounding region, to a definite value determined by the applied grid potential, otherwise 
ignition will not occur. The off-time, $\tau_{\text {off, }}$ required for the $\mathrm{Cs}$ atom density in the gap to reach the value required for ignition, $\mathrm{n}_{\mathrm{aj}}$, may be expressed as:

$$
\tau_{\text {off }}=\frac{\Delta N_{a}}{\left(\Gamma_{\mathrm{a} 0}-\Gamma_{\mathrm{a}}^{m}\right) \mathrm{S}}
$$

where $\Gamma_{\mathrm{a}} \mathrm{m}$ is the mean atom flux leaving the gap during the discharge and $\Delta \mathrm{N}_{\mathrm{a}}$ is the increase in the amount of $\mathrm{Cs}$ atoms in the gap during $\tau_{\text {off }}$, which is given by:

$$
\Delta N_{a}=\left(n_{a i}-n_{a e}\right) V_{g a p}+\Delta \sigma_{a} A_{g} c
$$

where $\mathrm{n}_{\mathrm{ai}}$ is the Cs density in the interelectrode gap necessary for ignition during modulation, $\mathrm{n}_{\mathrm{ae}}$ is the $\mathrm{Cs}$ atom density in the interelectrode gap after extinguishing, and $\mathrm{A}_{\mathrm{gC}}$ is the sum of the surface areas of the grid and collector. For Eq. (11), $\Delta \sigma_{\mathrm{a}}$ is the change in the Cs surface atom density on the grid and collector surfaces and is a function of the net adsorption/desorption of Cs atoms onto these surfaces during the off-time. If it is assumed that the surface density at the operating temperature of the grid and collector coincide with a monolayer coating of cesium $\left(2 \times 10^{14}\right.$ atoms $\left./ \mathrm{cm}^{2}\right)$, then $\Delta \sigma_{\mathrm{a}}$ can be given by:

$$
\Delta \sigma_{\mathrm{a}}-2 \times 10^{14}\left[\frac{\left(\mathrm{n}_{\mathrm{ai}}-\mathrm{n}_{\mathrm{ae}}\right)}{\mathrm{n}_{\mathrm{a} 0}}\right] \text { atoms } / \mathrm{cm}^{2} .
$$

Also, $\Gamma_{\mathrm{a}}{ }^{\mathrm{m}}$ is given by:

$$
\Gamma_{\mathrm{a}}^{\mathrm{m}}=\frac{1}{4} \overline{\mathrm{v}}_{\mathrm{a}} \frac{\left(\mathrm{n}_{\mathrm{ai}}+\mathrm{n}_{\mathrm{ae}}\right)}{2}-\frac{1}{4} \overline{\mathrm{v}}_{\mathrm{a}} \mathrm{n}_{\mathrm{ai}} .
$$

Therefore, substituting Eqs. (11) through (13) into Eq. (10) gives: 


$$
\tau_{\text {off }}=\left(n_{a i}-n_{a e}\right)\left\{\frac{V_{g a p}+\frac{2 \times 10^{14}}{n_{a} 0} A_{g C}}{\frac{S \overline{V_{a}}}{4}\left(n_{a 0}-n_{a i}\right)}\right\} .
$$

The first term in the numerator is the net change in the amount of Cs atoms in the gap during the off-time, and the second term accounts for the net adsorption/desorption of $\mathrm{Cs}$ atoms onto/from the surface of the grid and collector during the off-time. From Eq. (14), $\mathrm{n}_{\mathrm{ai}}$ can be expressed as:

$$
\mathrm{n}_{\mathrm{ai}}=\frac{S \mathrm{n}_{\mathrm{a} 0} \tau_{\text {off }} \overline{\nabla_{\mathrm{a}}}+4 \mathrm{n}_{\mathrm{ae}}\left(V_{\mathrm{gap}}+\frac{2 \times 10^{14}}{\mathrm{n}_{\mathrm{a} 0}} A_{\mathrm{g}}\right)}{\mathrm{S} \tau_{\text {off }} \overline{\bar{V}_{\mathrm{a}}}+4 V_{\mathrm{gap}}+\frac{8 \times 10^{14}}{n_{\mathrm{a} 0}} A_{\mathrm{g} C}}
$$

If the net adsorption of Cs atoms onto the surfaces during the off-time is negligible, then $\Delta \sigma_{a}$ could be set equal to zero, and Eqs. (14) and (15) are reduced respectively to:

$$
\tau_{\mathrm{off}}=\frac{\left(\mathrm{n}_{\mathrm{ai}}-\mathrm{n}_{\mathrm{ae}}\right) \mathrm{V}_{\mathrm{gap}}}{\frac{\mathrm{S} \overline{\mathrm{V}}_{\mathrm{a}}}{4}\left(\mathrm{n}_{\mathrm{a} 0}-\mathrm{n}_{\mathrm{ai}}\right)},
$$

and

$$
n_{a i}=\frac{S n_{a 0} \tau_{\text {off }} \overline{V_{a}}+4 n_{a e} V_{g a p}}{S \tau_{\text {off }} \bar{V}_{a}+4 V_{g a p}}
$$

Equations (14) and (16) give the off-time required for successful ignition at a certain Cs reservoir temperature and applied grid potential with and without the effects of Cs adsorption, respectively. Equations (15) and (17) give the required Cs density in the gap for successful ignition as a function of the measured operating conditions ( $\mathrm{P}_{\mathrm{Cs}}$ and $\mathrm{T}_{\mathrm{gap}}$ ) and the off-time, with and without the effect of Cs adsorption onto the cold electrode surfaces, respectively. To ascertain the effect of the Cs adsorption on the off-time during stable current modulation, the calculated value of $n_{a i}$ is 
compared with the values determined from the measured Cs pressure in the gap during the breakdown mode of operation of the device.

Experimental measurements are made of the collector voltage, $V_{C E}$, for ignition in the breakdown mode as a function of the following operation parameters: (a) applied positive potential to the grid, $\mathrm{V}_{\mathrm{g}_{+}}$, (b) Cs reservoir temperature, $\mathrm{T}_{\mathrm{Cs}}$, (c) Ba reservoir temperature, $\mathrm{T}_{\mathrm{Ba}}$, and (d) emitter temperature, $\mathrm{T}_{\mathrm{E}}$. This data is used to measure the $\mathrm{Cs}$ atom density required for ignition to occur at a given $\mathrm{V}_{\mathrm{g}+}$ and calculate the off-time, $\tau_{\mathrm{off}}$, required to reach this density for a given set of operating conditions.

The $P_{\text {gap }} d$ values in Fig. 7 directly correspond to the densities of $\mathrm{Cs}$ atoms, $\mathrm{n}_{\mathrm{a} 0}$, in the gap required to successfully ignite the Cs-Ba tacitron, at the given grid voltage, in the breakdown mode. To determine the effect of the net Cs adsorption occurring during the off-time of stable current modulation, the value of $n_{a i}$ calculated from Eq. (15) and (17) are compared to these values corresponding to the Cs pressure for ignition in the breakdown mode from Fig. 7. To achieve this, the off-time during current modulation is measured, and the results are shown in Fig 11. As can be seen in Fig. 11, the off-time required for ignition during stable current modulation decreases as the Cs pressure is increased. For $\mathrm{Vg}+$ less than $20 \mathrm{~V}\left(\tau_{\mathrm{off}} \sim 260 \mu \mathrm{s}\right)$, a large jump in the off-time occurs because current modulation becomes unstable; whereas $f_{m}<f_{g}$. During unstable current modulation, ignition of the discharge occurs when a positive potential is applied to the grid, but the discharge fails to extinguish intermittently when a negative potential is applied to the grid, resulting in a longer off-time (see Fig. 9). Based on the results presented in Fig. 11, it is concluded that a necessary condition for the calculation of $n_{a i}$ at $f_{g}=3 \mathrm{kHz}$ is that $\tau_{\text {off }} \leq 260 \mu s$.

Figure 12 shows the calculated and measured $\mathrm{P}_{\text {gap }}$ d values for ignition in the stable current modulation and the breakdown mode, as a function of $V_{g+}$ for $T_{C s}=155^{\circ} \mathrm{C}, f_{g}=3 \mathrm{kHz}, T_{E}=$ $1200^{\circ} \mathrm{C}$, and $\mathrm{T}_{\mathrm{Ba}}=500^{\circ} \mathrm{C}$. The calculated values are obtained from the stable current modulation off-times measurements (see Fig. 11). As can be seen in Fig. 12, the calculated values of $P_{\text {gap }}$ d for ignition during stable current modulation with a net Cs adsorption term (Eq. (15)) approximately $0.003 \mathrm{~mm}$-torr, is almost independent of $\mathrm{V}_{g_{+}}$, and far from the measured $\mathrm{P}_{\text {gand }}$ 


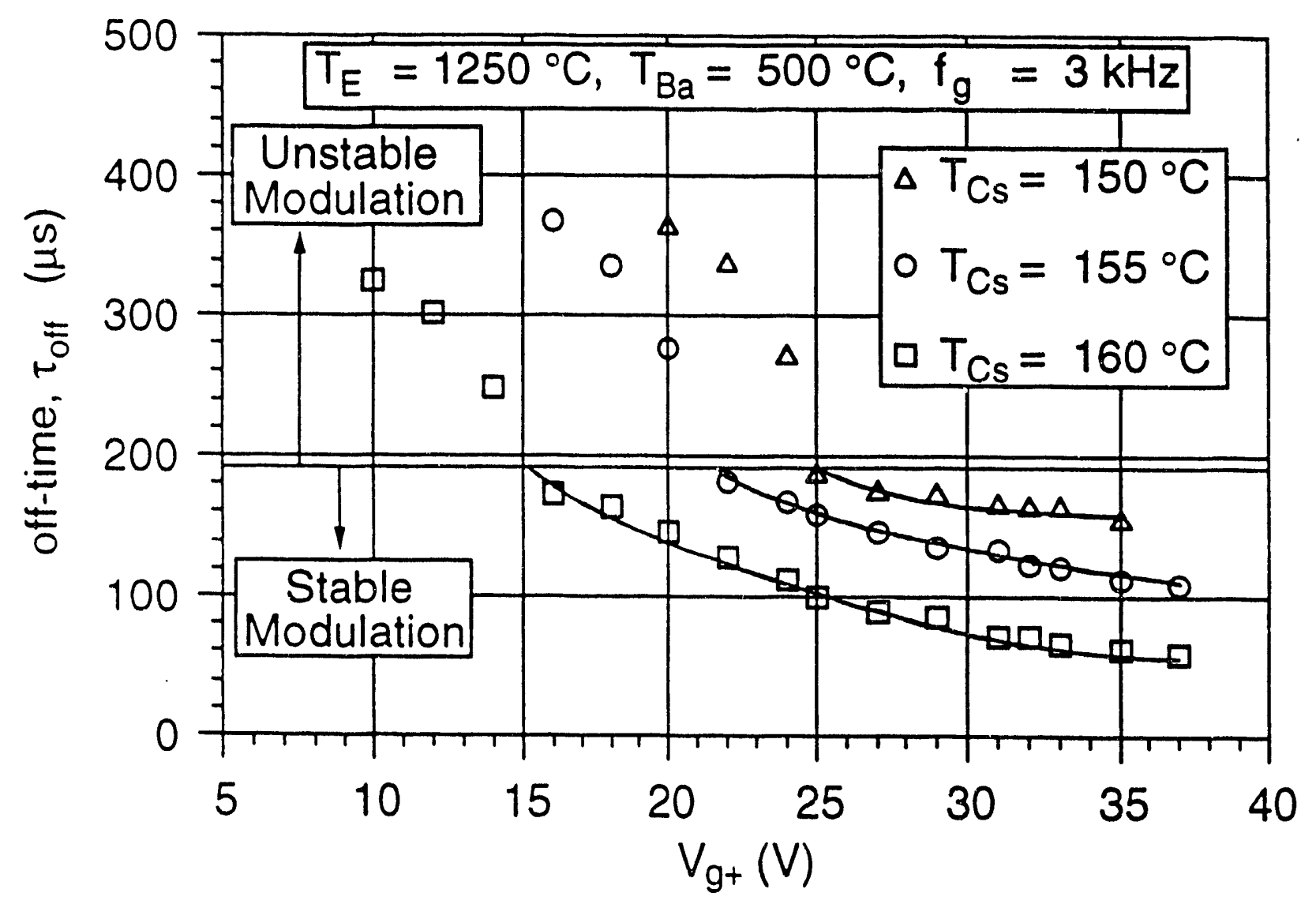

Figure 11. Effect of Cesium Reservoir Temperature on the Off-Time During Current Modulation. 


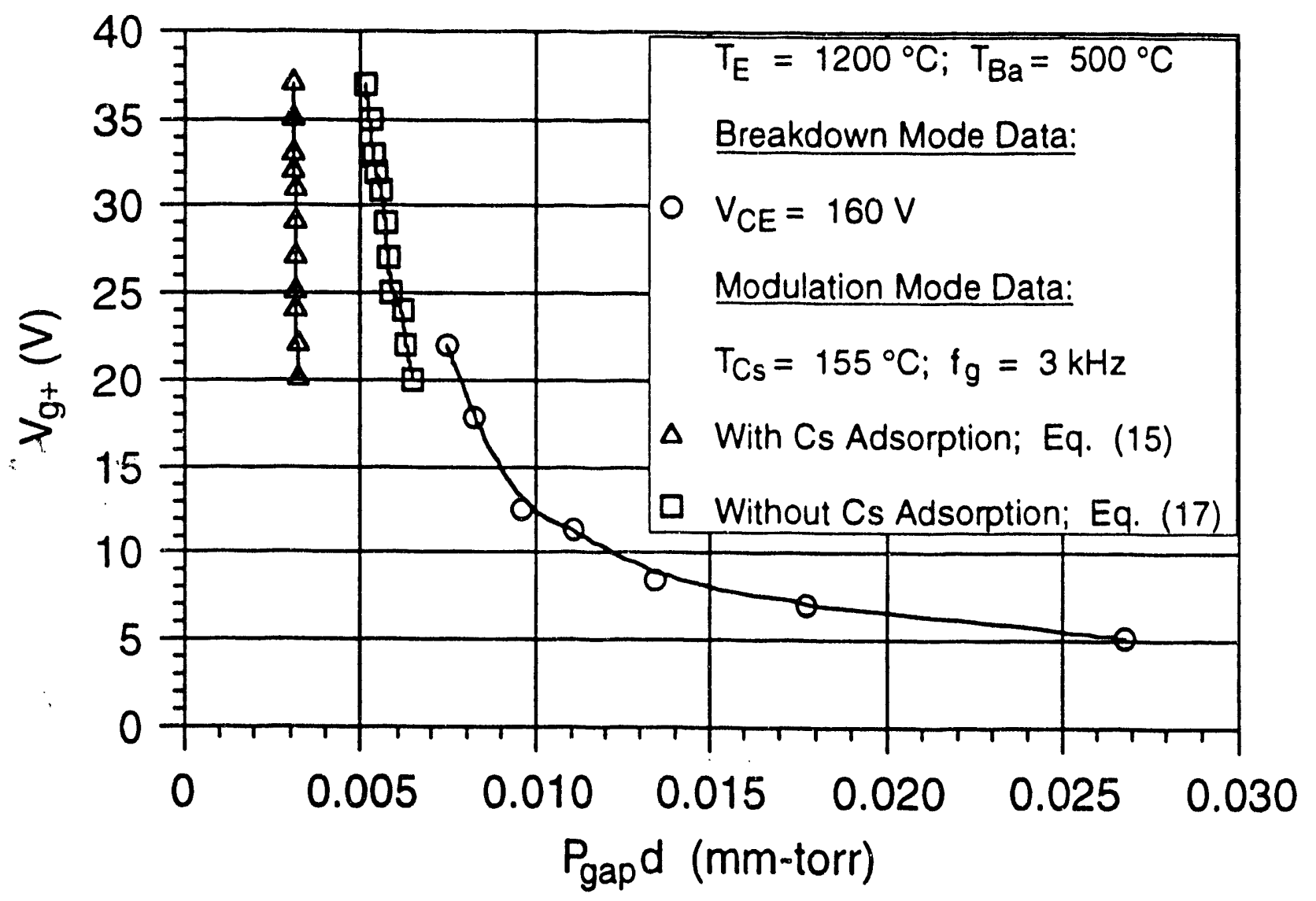

Figure 12. Comparison of $P_{\text {gap }}$ d Values for Ignition in the Breakdown and Current Modulation Modes. 
values for ignition in the breakdown mode. On the other hand, using the formulation without a net Cs adsorption during the off-time (Eq. (17)), the calculated $P_{\text {gap }} d$ values lie close to those from the breakdown mode. Such close agreement suggests that the effects of Cs adsorption, if any, insignificantly influences the off-time required to restore the Cs density in the gap in order for ignition to occur during stable current modulation.

With the switching characteristics of a Cs-Ba tacitron outlined above, the next section deals with using two Cs-Ba tacitrons in an inverter configuration. The effects the inverter circuit has on the operation of each individual switch is discussed, as well as, experimental results at the output of the step-up pulse transformer.

\section{CS-Ba TACITRONS IN AN INVERTER CONFIGURATION}

The inverter assembly consists of two Cs-Ba tacitrons operating in a push-pull configuration, a grid modulation circuit, and a step-up pulse transformer circuit. During modulation, discharge is ignited in one tacitron by applying a short duration, positive potential pulse to its grid. At the same time, discharge is extinguished in the second tacitron by applying a negative potential pulse to the grid, or by rapidly lowering the collector potential below that necessary for sustaining the discharge. This process is repeated in a reversed order generating an alternating low voltage/high current signal of square pulses. This signal is then converted to a high voltage/low current A.C. signal via the use of a step-up pulse transformer. The performance parameters of the inverter are directly related to the current modulation characteristics of the tacitrons (i.e. efficiency, frequency, duty cycle, etc.) as w'ell as the current interruption method used to extinguish the discharge. Depending on the latter, the inverter can be operated in one of two modes: the thyratron mode or the tacitron mode. In the first mode, the discharge in the Cs- $\mathrm{Ba}$ switches is ignited by applying a positive potential pulse to the grids, but the current is interrupted by lowering the collector potential below that necessary for sustaining the discharge through the use of reactive components in the inverter circuit (i.e. capacitors or inductors). The semi-conductor thyristors and gas discharge thyratrons belong in this category. 


\subsection{Cs-Ba Tacitron Inverter Operating in the Thyratron Mode}

A schematic of the inverter operating in the thyratron mode is shown in Fig. 13. During modulation, discharge is ignited in one tacitron, $S_{1}$, by applying a short duration, positive potential pulse, $\mathrm{V}_{\mathrm{g} 1}$, to its grid. At the same time, discharge is extinguished in the second tacitron, $\mathrm{S}_{2}$, because the capacitor, $C$,. reverse biases the collector of $S_{2}$ which causes the current to be interrupted. Reverse biasing of the second tacitron $\left(S_{2}\right)$ occurs after the first tacitron $\left(S_{1}\right)$ is ignited. This process is repeated in a reversed order generating an alternating low voltage/high current signal of square pulses. These signals are then converted to a high voltage/low current A.C. signal via the use of a step-up pulse transformer. The winding ratio for the transformer for the experimental data discussed is (1:2') 1:10. The disadvantages of this type of inverter circuit are the large power dissipation in the reactive element and the relatively low modulation frequency. However, the advantage of operating in the thyratron mode is that stable modulation can occur at high Cs vapor pressures, resulting in lower voltage drop in the tacitron switch $(-2-2.5 \mathrm{~V})$. Another advantage of operating in the thyratron mode is that the operation characteristics of the inverter are insensitive to changes in the Cs vapor pressure in the tacitrons. The value of the capacitance is defined by the time necessary to interrupt the current in the switch that was initially on.

In the thyratron mode inverter, stable modulation was observed for Cs pressures ranging from $5 \times 10^{-3}$ torr to $2 \times 10^{-2}$ torr. Typical plots of the current and voltage characteristics are shown in Fig 14. These figures show the collector and grid voltages and currents for the top triode section (left plot), bottom triode section (middle plot), a mix of the collector current and voltage in the top section (right plot-upper curves), and the grid current and voltage in the bottom section (right plotlower curves). At almost the same time the discharge in the bottom tacitron was ignited, which is indicated by the increase in the grid current (see right plots in Fig. 14), the collector voltage for the top section decreased, causing the discharge to extinguish. As the discharge was ignited in the bottom triode, (top-middle plot in Fig 14) the collector current initially increased to a value ( $>36$ A) that is greater than the steady-state current, which is determined by the inverter circuit ( $-15 \mathrm{~A}$ ) 


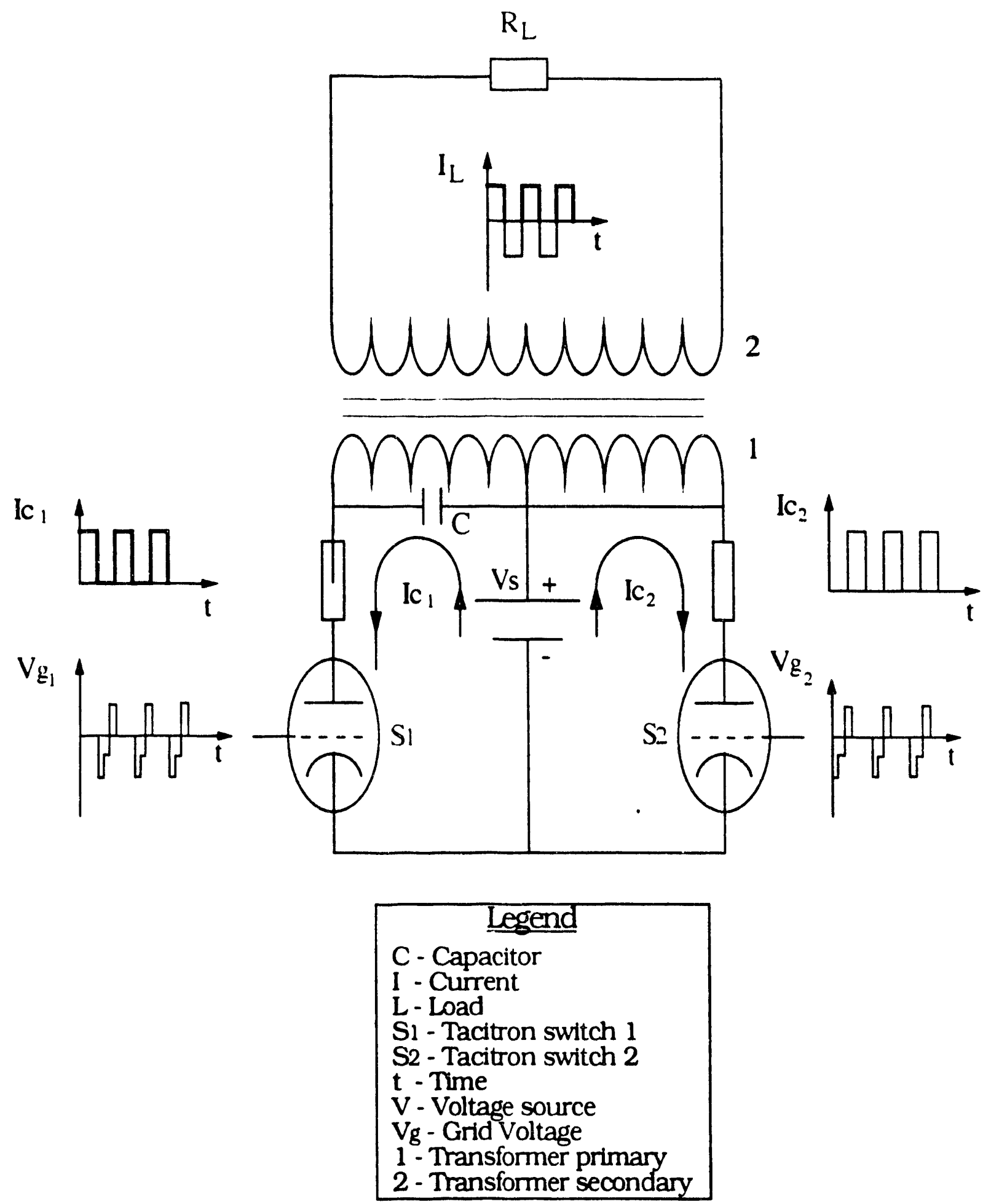

Figure 13. Inverter Circuit for Thyratron Mode Operation. 


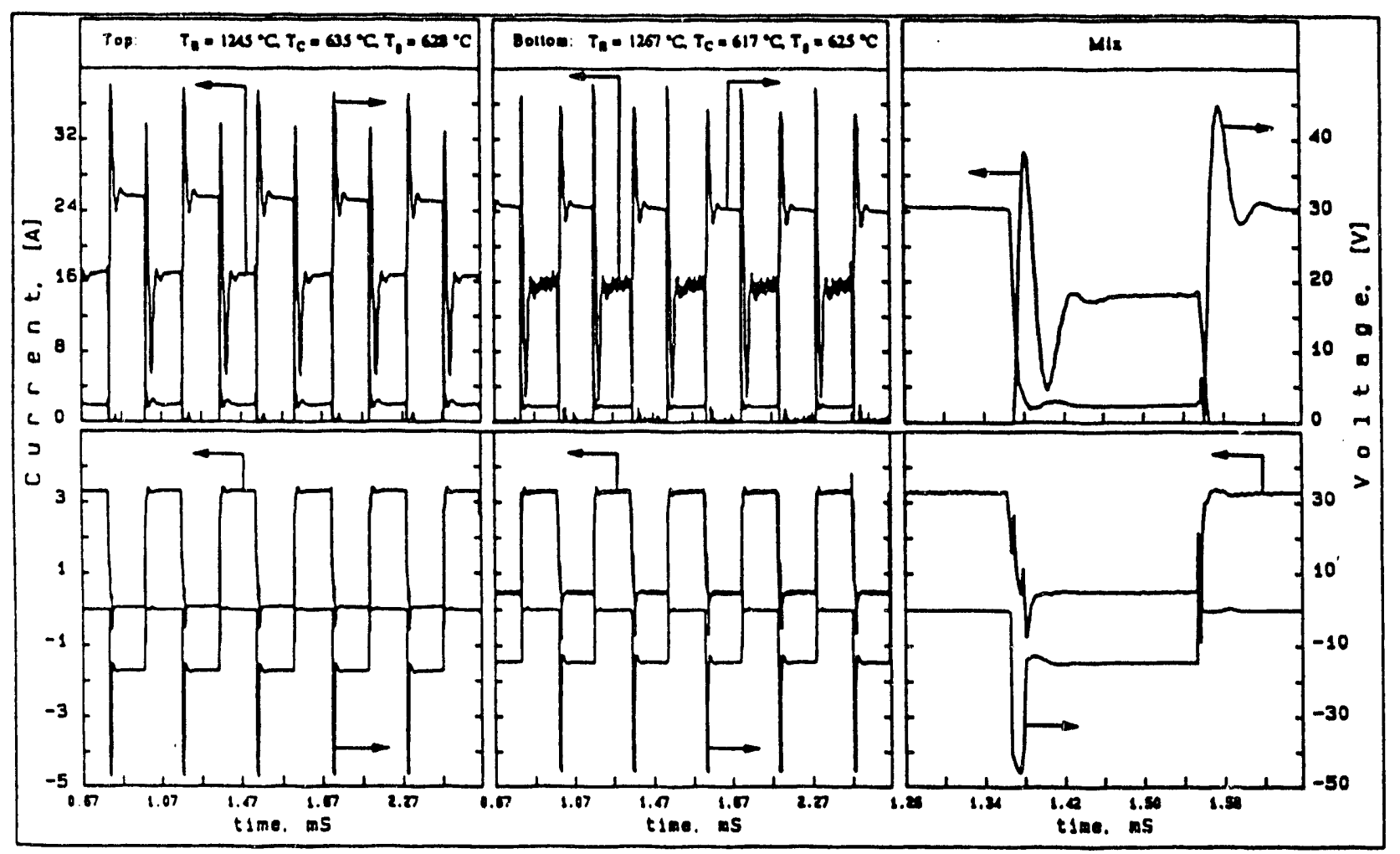

Figure 14. Voltages and Currents for the Top and Bottom Tacitrons While Operating in the Thyratron Mode $\left(\mathrm{T}_{\mathrm{Cs}}=143^{\circ} \mathrm{C}, \mathrm{T}_{\mathrm{Ba}}=556^{\circ} \mathrm{C}\right.$, and $\left.\mathrm{f}_{\mathrm{g}}=2.7 \mathrm{kHz}\right)$. 
This high current spike is the sum of the current passing through the primary lead of the transformer and the current for recharging the capacitor. These figures also show that at the time of discharge extinguishing in the top section, a voltage spike occurs simultaneously on the collector of the top section (top-left plot) as a result of the self-induction of the transformer. These overshoots, in the collector current and voltage, are typical of the transient response of inverter circuits that utilize capacitors or inductors. After the voltage and current spikes subside, the collector current and voltage characteristics become similar to those seen in a single tacitron when operated as a switch, without the inverter circuit connected. The demonstrated operating characteristics of the $-\mathrm{Ba}$ tacitron inverter in the thyratron mode are discharge currents up to 20 . A, collector voltage of up to $32 \mathrm{~V}$, voltage drop of about $2.5 \mathrm{~V}$, and a modulation frequency up to $10 \mathrm{kHz}$. Typical results of the voltage and current to the load (secondary of the transformer) in the thyratron mode of operation are shown in Figs. 15(a) and 15(b), at a modulation frequency of 2.8 $\mathrm{kHz}$ and $10 \mathrm{kHz}$, respectively. It can be seen that the shapes of the voltage and current curves are very close to a square wave even at frequencies as high as $10 \mathrm{kHz}$.

\subsection{Cs-Ba Tacitron Inverter Operating in the Tacitron Mode}

When the inverter is operated in the tacitron mode, discharge extinguishing is induced by applying a negative pulse to the grid. The semiconductur transistor and gas discharge tacitron operate in this mode. The inverter circuit used for operating in the tacitron mode is the same as that for operating in the thyratron mode, but without the capacitor (see Fig. 13). During current modulation, discharge ignition occurs in the same manner as in thyratron mode; which is by applying a short duration, positive potential pulse, $\mathrm{V}_{\mathrm{g} l}$, to its grid. However, unlike in the thyratron mode, the discharge is extinguished in the second tacitron, $\mathbf{S}_{2}$, by applying a negative potential pulse to the grid, $\mathrm{V}_{\mathrm{g} 2}$. This process is repeated in a reversed order generating an alternating low voltage/high current signal of square pulses. The rest of the inverter circuit is the same as that discussed for thyratron mode of operation. In the tacitron mode of operation, the absence of high power reactive components in the inverter circuit enables operation at higher 
(a)

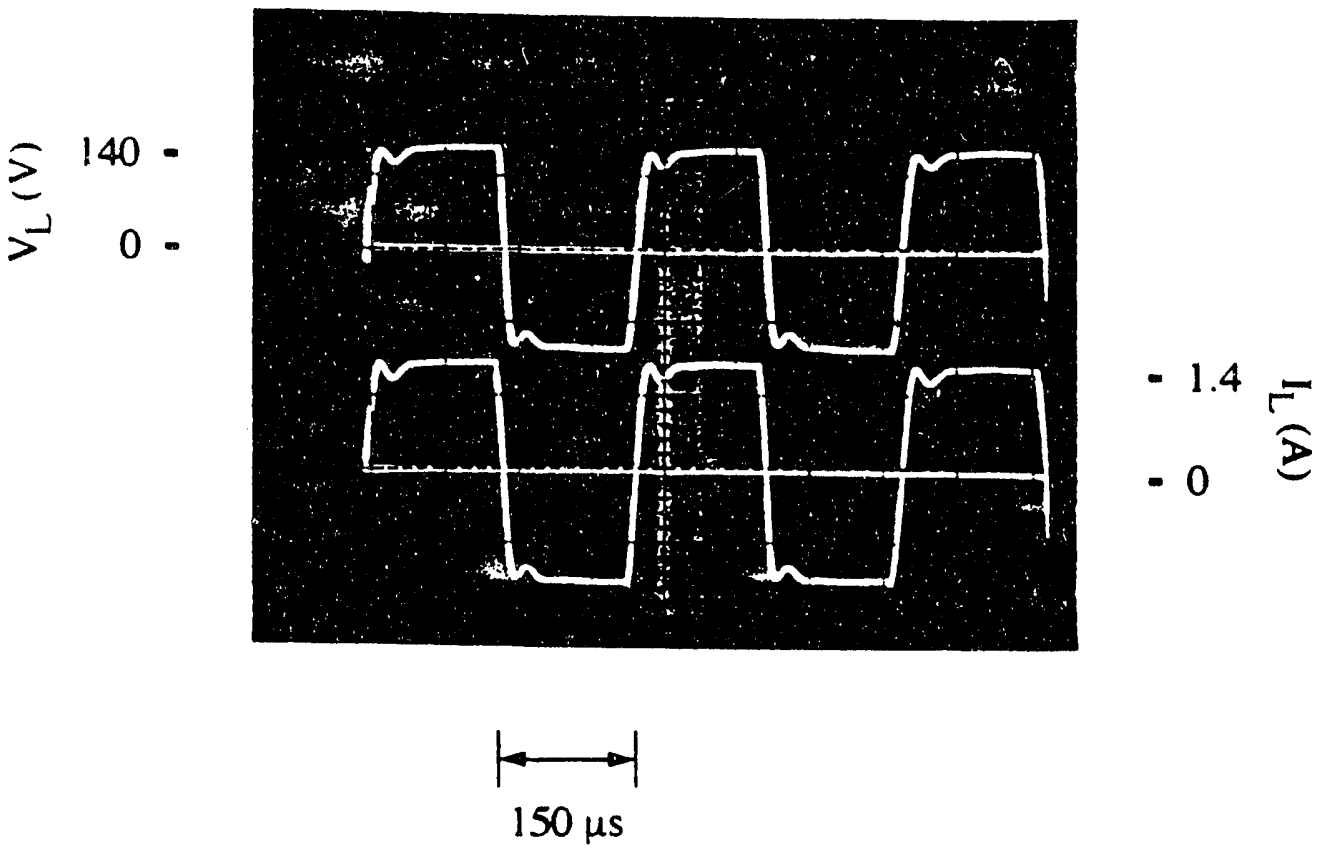

(b)

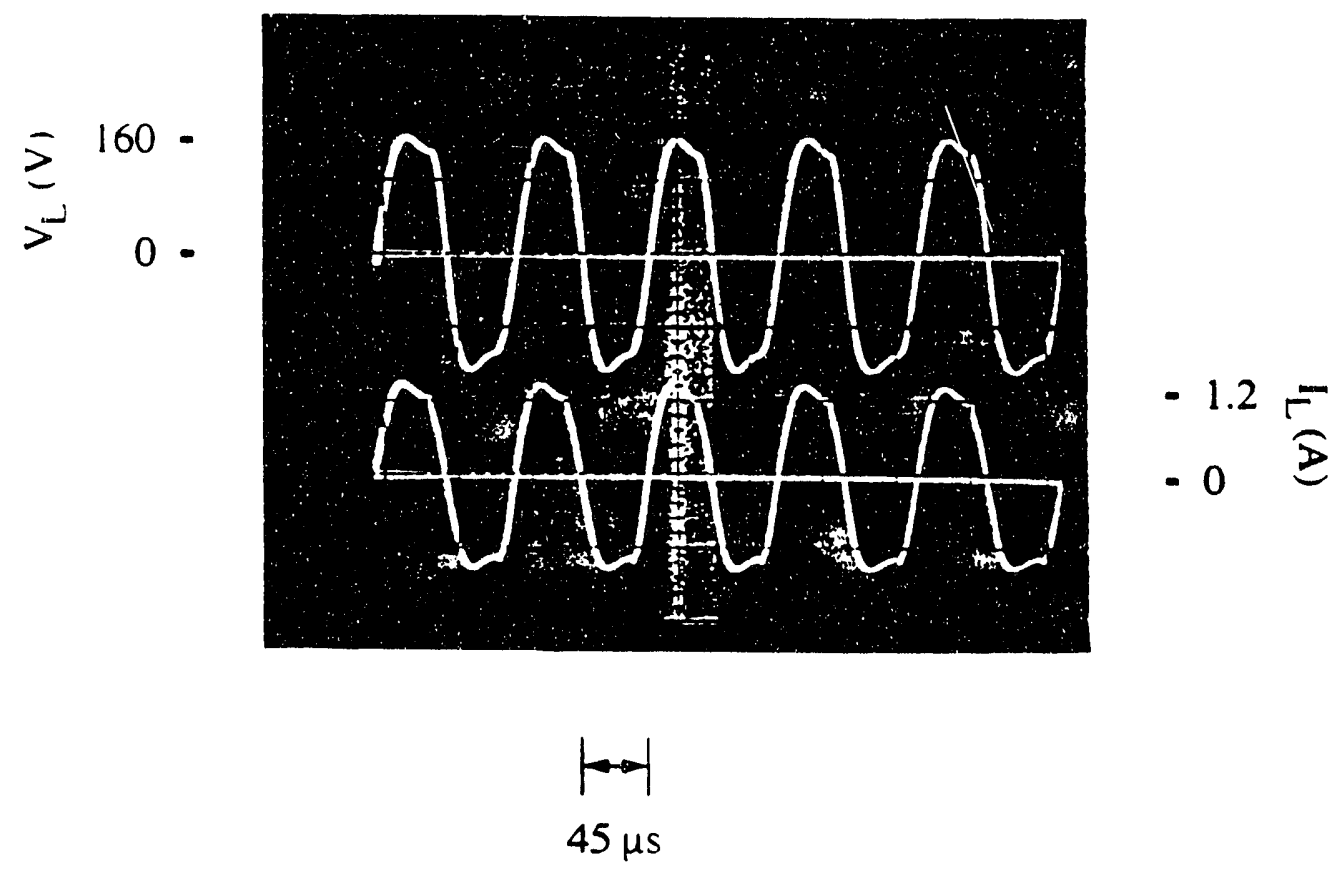

Figure 15. Voltage and Current from the Pulse Transformer While Operating the Inverter in the Thyratron Mode, (a) $\mathrm{f}_{\mathrm{g}}=2.7 \mathrm{kHz}$ and $(b) \mathrm{f}_{\mathrm{g}}=10.6 \mathrm{kHz}$. 
modulation frequencies, and the slightly larger voltage drop in the tacitrons can be compensated for by the absence of power dissipation in reactive components, as in the thyratron mode.

In the tacitron mode of inverter operation, the frequency characteristics are better than in the thyratron mode, which can be seen by comparing the rise-times and fall-times for each mode of operation. However, in the tacitron mode, stable modulation is observed at low Cs vapor pressures resulting in a higher voltage drop than in the thyratron mode. Also two different grid geometries were investigated in this mode of operation. The first grid has a hole diameter of 0.8 $\mathrm{mm}$ (large aperture grid) and a thickness of $1.0 \mathrm{~mm}$ and the second grid has a hole diameter of 0.4 $\mathrm{mm}$ (small aperture grid) and a thickness of $0.5 \mathrm{~mm}$.

\subsubsection{Inverter Characteristics with the Large Aperture Grid}

As shown in Fig. 16, at a modulation frequency of about $4 \mathrm{kHz}$, the voltage drop in each tacitron is about $3-3.5 \mathrm{~V}$. Fig. 17 also demonstrates that at a modulation frequency of $10 \mathrm{kHz}$, the shapes of the current and voltage wave forms at the load have the same square wave appearance as in the thyratron mode (see Fig. 16), but with much steeper rise and fall characteristics. This reduction in the rise and fall times, when operating in the tacitron mode, is more apparent when operating at higher frequencies. The highest frequency measured in the tacitron inverter mode was on the order of $20 \mathrm{kHz}$; this maximum was due to limitations of the grid pulse generator, not in the tacitrons. As seen in Fig. 17(b), even at this high frequency, the shape of the current and voltage pulses on the load is very close to square waves.

Also with the large aperture grid it was possible to modulate a discharge current of $3.5 \mathrm{~A}$, collector voltage of $32 \mathrm{~V}$ at a frequency of $6.5 \mathrm{kHz}$ and forward conduction drop of $3 \mathrm{~V}$, which can be seen in Fig. 18. The load voltage and current, $\mathrm{V}_{\mathrm{L}}$ and $\mathrm{I}_{\mathrm{L}}$, at the secondary of the transformer shown in Fig. 19 were $150 \mathrm{~V}$ and $0.32 \mathrm{~A}$, respectively. Figure 20 shows the voltage and current characteristics at a modulation frequency of $20 \mathrm{kHz}$ with the larger aperture size grid. The current and voltage at the secondary of the transformer are shown in Fig. 18(b). As can be seen in these figures, the discharge current and voltage were $1.6 \mathrm{~A}$ and $30 \mathrm{~V}$, respectively; the 


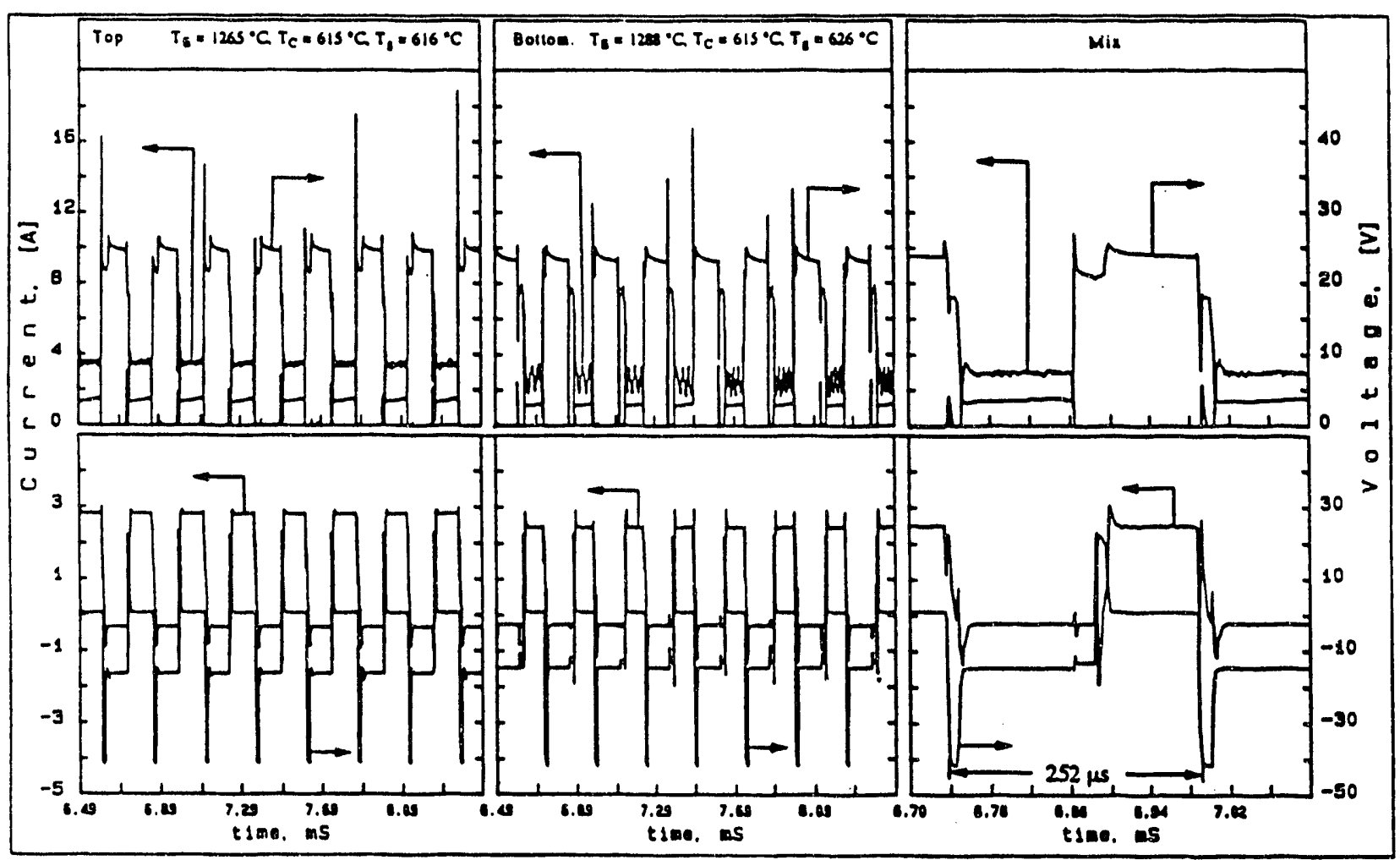

Figure 16. Voltages and Currents for the Top and Bottom Tacitrons While Operating in the Tacitron Mode $\left(\mathrm{T}_{\mathrm{Cs}}=137^{\circ} \mathrm{C}, \mathrm{T}_{\mathrm{Ba}}=554^{\circ} \mathrm{C}\right.$, and $\left.\mathrm{f}_{\mathrm{g}}=3.97 \mathrm{kHz}\right)$. 
(a)

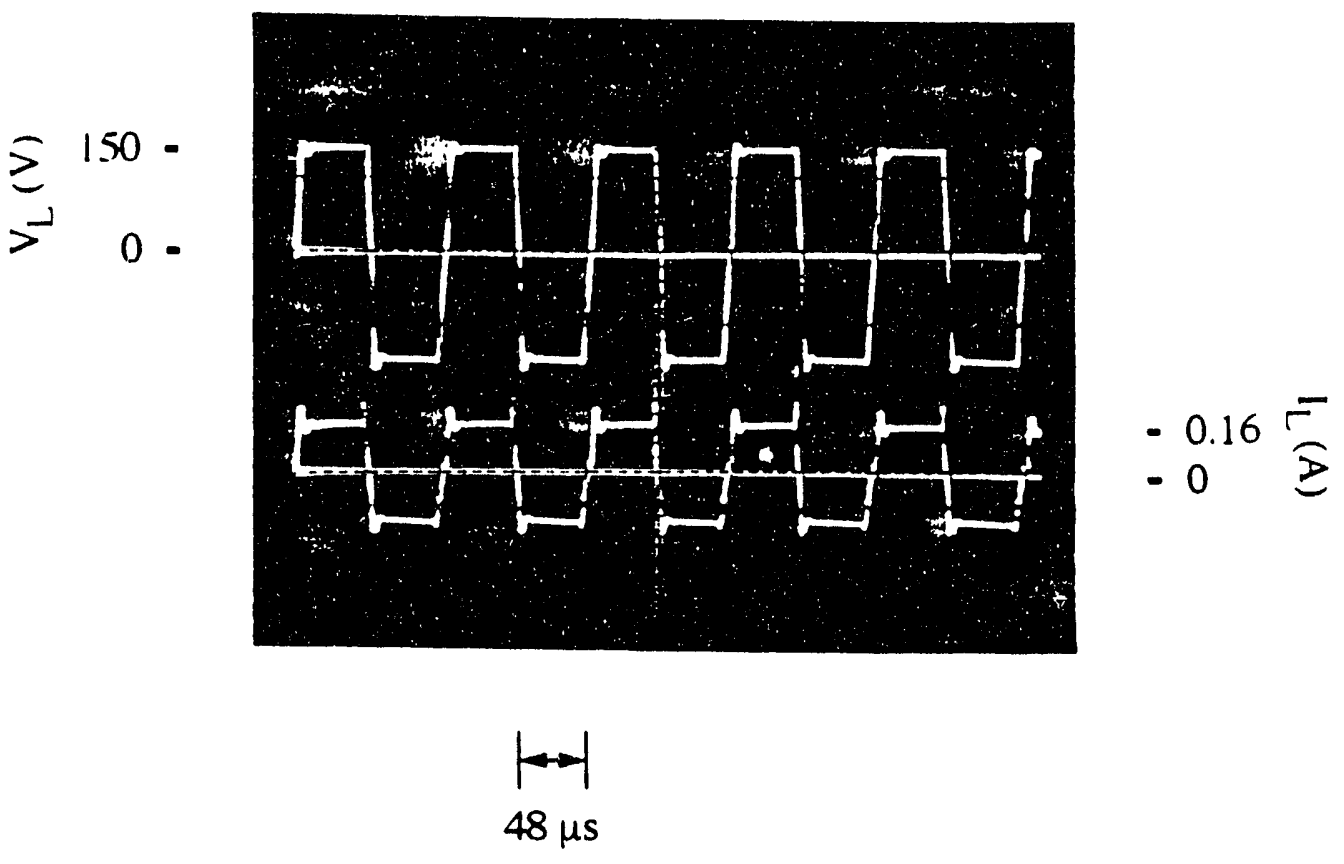

(b)

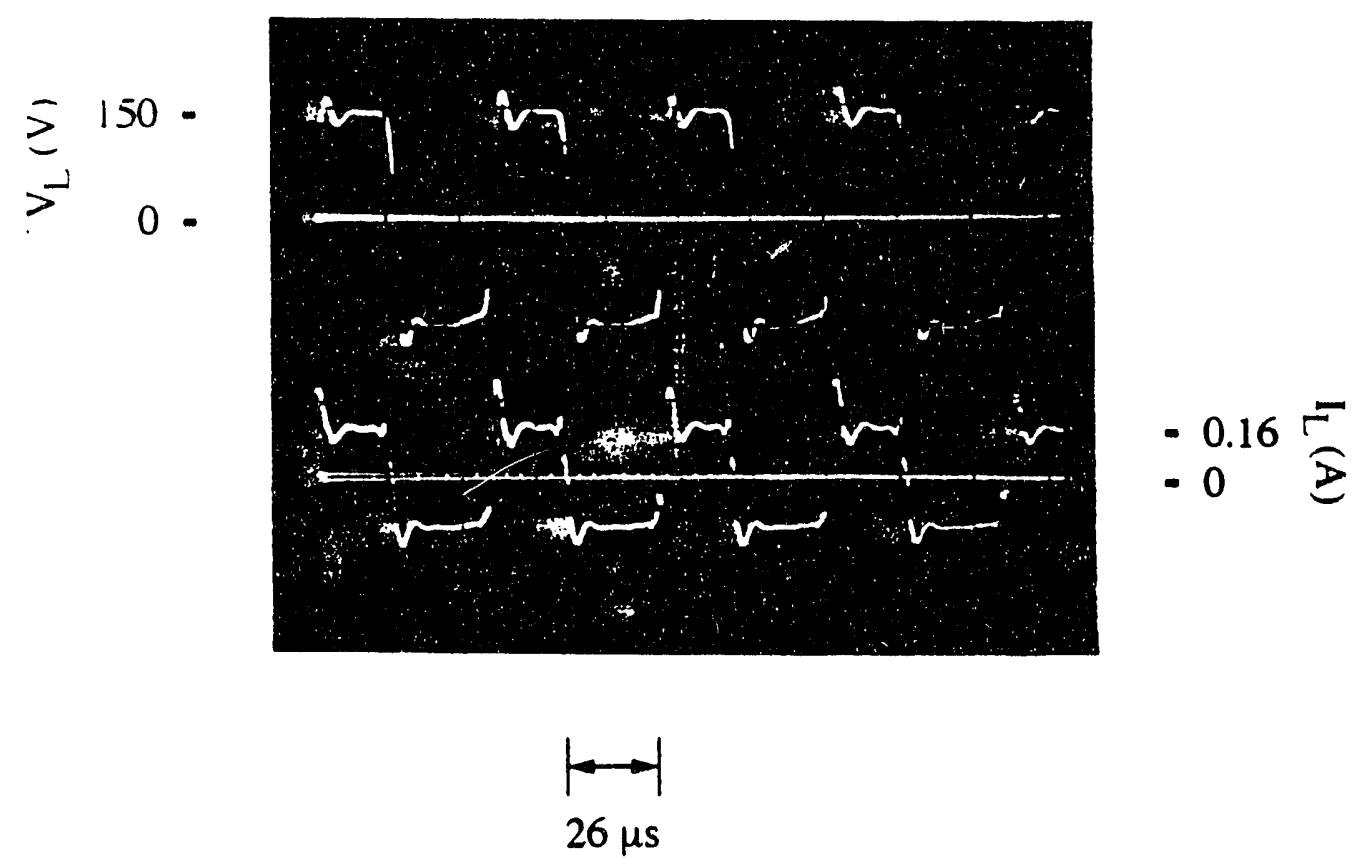

Figure 17. Voltage and Current from the Pulse Transformer While Operating the Inverter in the Tacitron Mode, (a) $f_{g}=10.6 \mathrm{kHz}$ and (b) $f_{g}=20.0 \mathrm{kHz}$. 


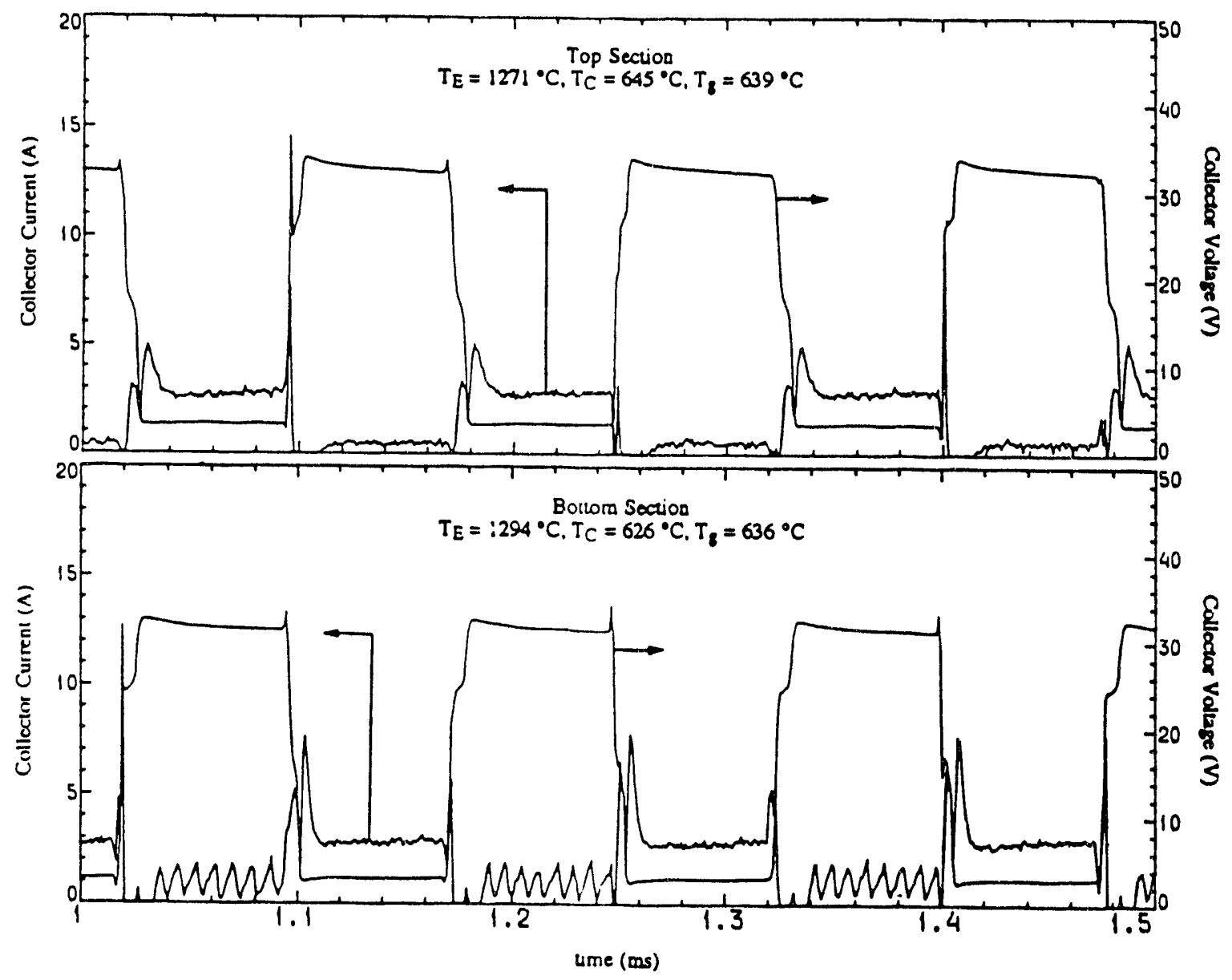

Figure 18. Measured Voltage and Current Signals with the Large Aperture Grid While Operating in the Tacitron Mode $\left(\mathrm{T}_{\mathrm{Cs}}=135^{\circ} \mathrm{C}, \mathrm{T}_{\mathrm{Ba}}=575^{\circ} \mathrm{C}\right.$, and $\left.\mathrm{f}_{\mathrm{g}}=6.5 \mathrm{kHz}\right)$. 


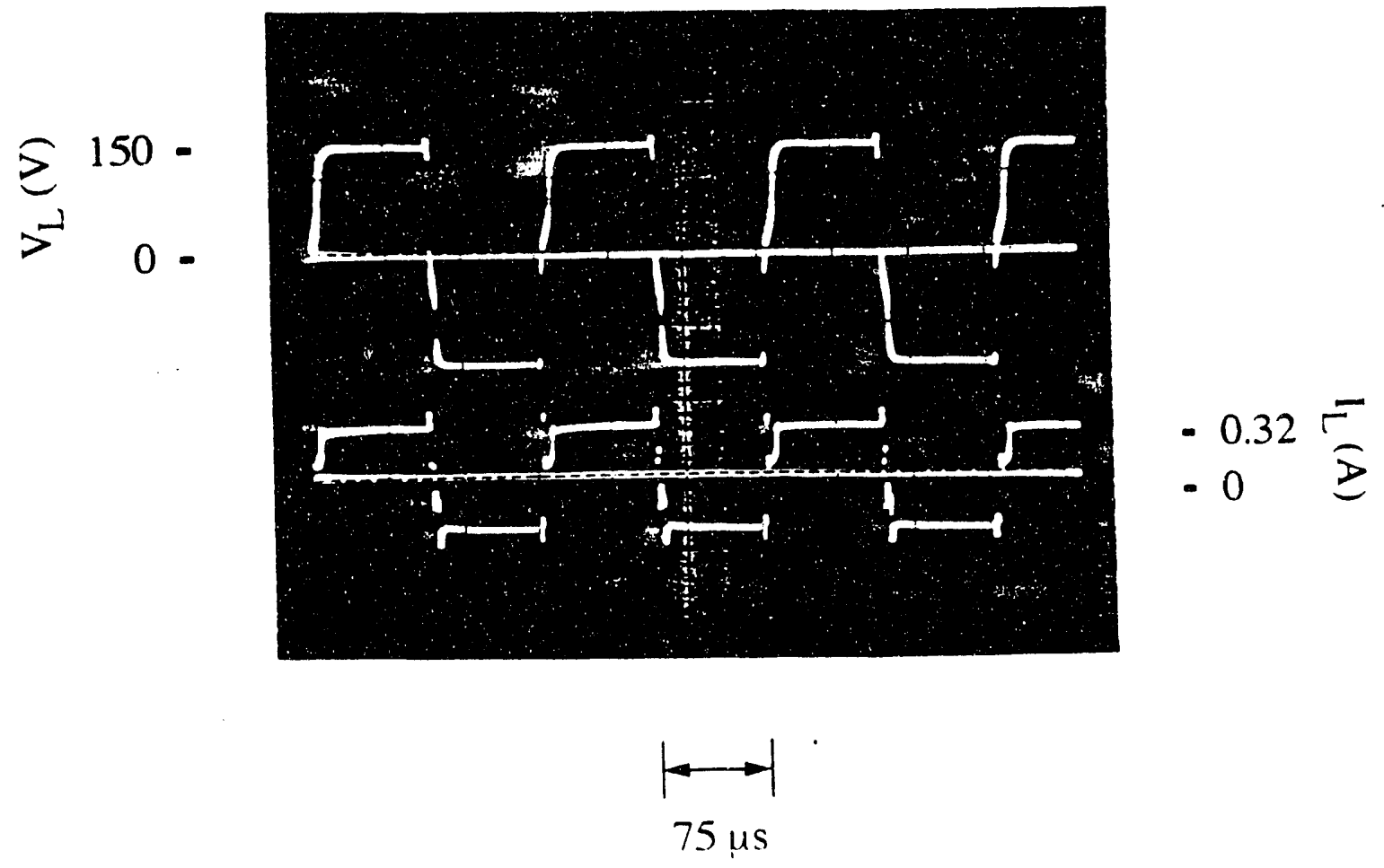

Figure 19. Measured Voltage and Current Signals with the Large Aperture Grid at the Output of the Step-Up Pulse Transformer While Operating in the Tacitron Mode $\left(\mathrm{T}_{\mathrm{Cs}}=135^{\circ} \mathrm{C}\right.$, $\mathrm{T}_{\mathrm{Ba}}=575^{\circ} \mathrm{C}$, and $\mathrm{f}_{\mathrm{g}}=6.5 \mathrm{kHz}$ ). 


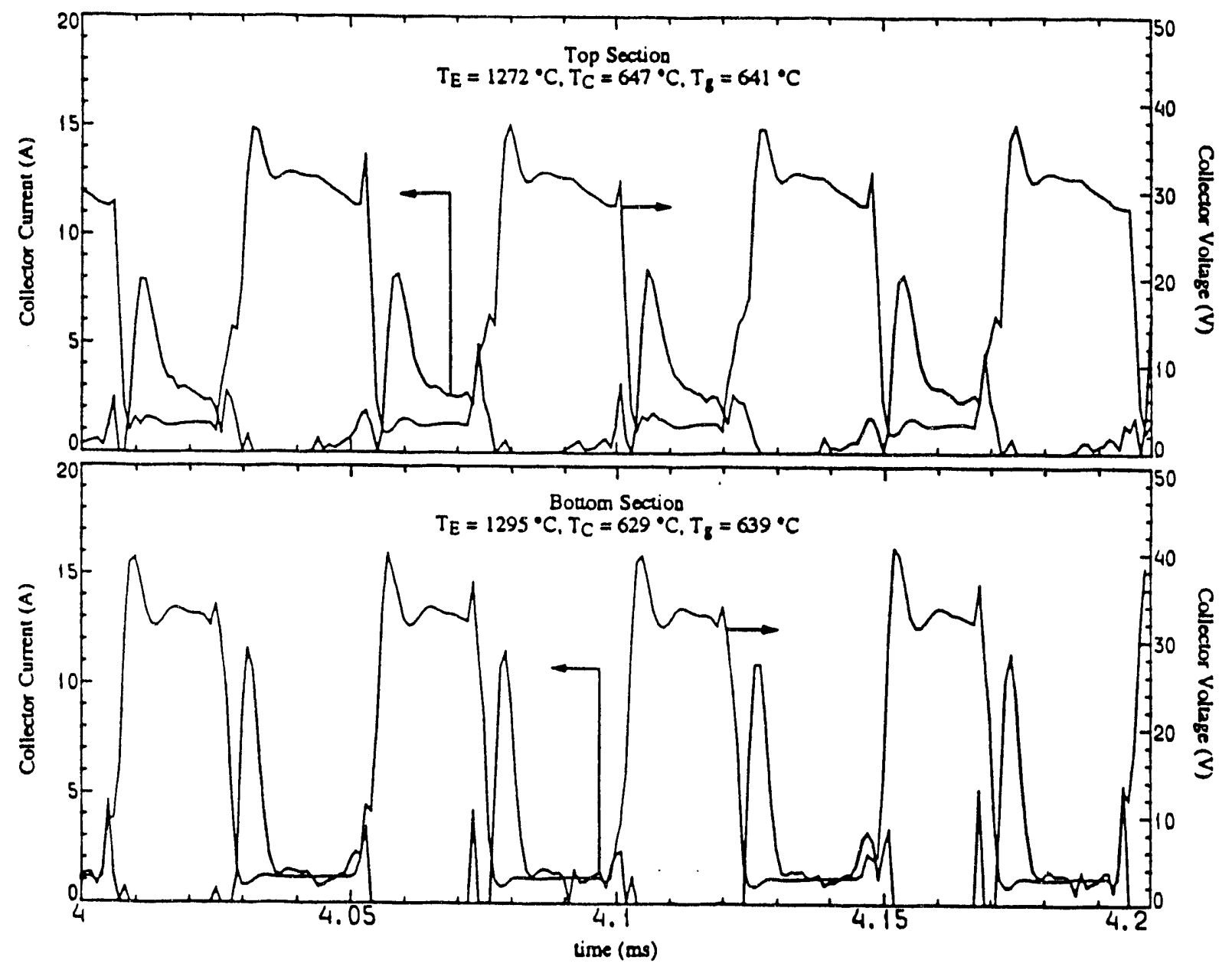

Figure 20. Measured Voltage and Current Signals with the Large Aperture Grid While Operating in the Tacitron Mode $\left(\mathrm{T}_{\mathrm{Cs}}=137^{\circ} \mathrm{C}, \mathrm{T}_{\mathrm{Ba}}=554^{\circ} \mathrm{C}\right.$, and $\left.\mathrm{f}_{\mathrm{g}}=20 \mathrm{kHz}\right)$. 
conduction voltage drop was less than $3 \mathrm{~V}$. The corresponding load current for this case was 0.16 A. The $20 \mathrm{kHz}$ modulation frequency was limited by the grid pulse generator and not necessarily the tacitron.

\subsubsection{Inverter Characteristics with the Small Aperture Grid}

With the small aperture grid, it was possible to operate the inverter at higher discharge currents for a given modulation frequency. Figure 21 shows the inverter again operating at $6 \mathrm{kHz}$, but with a discharge current of $13.5 \mathrm{~A}$, collector voltage of $24 \mathrm{~V}$ and forward conduction drop of 4 V. Figure 22 illustrates the voltage and current waveforms at the output of the transformer. It can be seen that the voltage is about $80 \mathrm{~V}$ and the current is about $1.2 \mathrm{~A}$, a 4 times increase from the current using the large grid aperture. The decrease in the voltage is a limitation of the voltage supply being used for the measurements.

There were also some changes in the switching characteristics associated with increasing the discharge current. The first, which can be seen easily in Figs. 21 and 22, is that the shape of the voltage and current waveforms are no longer square. This is an effect of the circuit and might be improved by optimizing the circuit design. The second effect of increasing the discharge current is the appearance of a delay before the tacitrons ignite after the positive pulse is applied to the grid. In Figs. 18 and 19 there was no delay between the decrease of the voltage and increase of the current in the device; whereas, in Fig. 21 there is a $10 \mu$ s delay. This delay can also be seen in Fig. 22. This delay time is due to the increased ion flux leaving the discharge during the on-time which prolongs the time needed to replenish the Cs atom density to the value necessary for ignition. The increased ion flux is primarily due to the higher ion density in the gap, since the forward voltage drop only increases from $3.5 \mathrm{~V}$ to $4 \mathrm{~V}$, which would result in a very small increase in the electron temperature. It is worth noting that the appearance of a delay time is solely due to the increase in the discharge current, and is independent of the size of the grid aperture.

Figures 23 and 24 show the inverter operating at $20 \mathrm{kHz}$ with the small aperture grid.

Again by using the smaller grid apertures, the current was increased from $0.16 \mathrm{~A}$ for the larger 


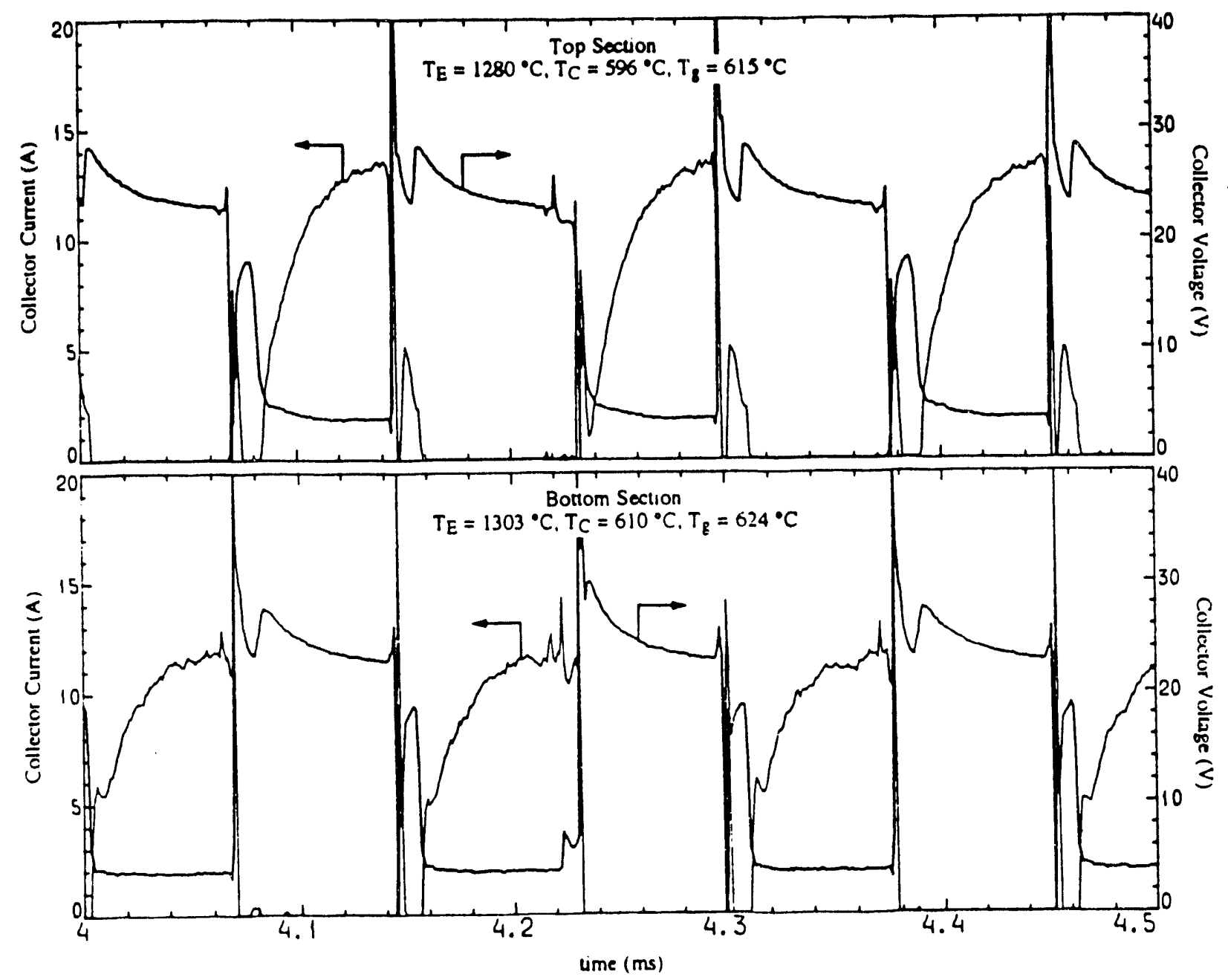

Figure 21. Measured Voltage and Current Signals with the Small Aperture Grid While Operating in the Tacitron Mode $\left(\mathrm{T}_{\mathrm{Cs}}=138^{\circ} \mathrm{C}, \mathrm{T}_{\mathrm{Ba}}=552^{\circ} \mathrm{C}\right.$, and $\left.\mathrm{f}_{\mathrm{g}}=6.5 \mathrm{kHz}\right)$. 


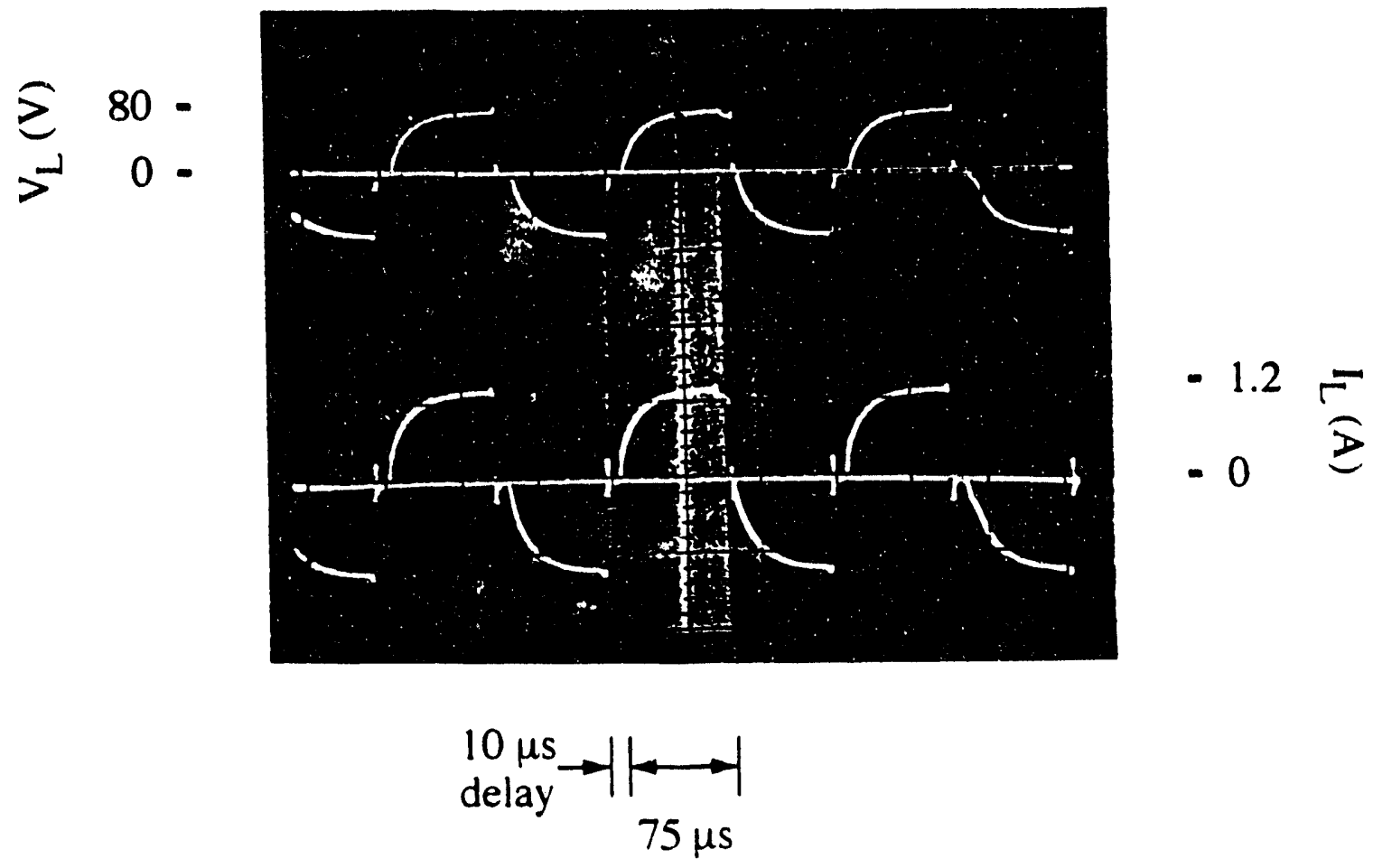

Figure 22. Measured Voltage and Current Signals with the Small Aperture Grid at the Output of the Step-Up Pulse Transformer While Operating in the Tacitron Mode $\left(\mathrm{T}_{\mathrm{Cs}}=138^{\circ} \mathrm{C}\right.$, $\mathrm{T}_{\mathrm{Ba}}=552^{\circ} \mathrm{C}$, and $\mathrm{f}_{\mathrm{g}}=6.5 \mathrm{kHz}$ ). 

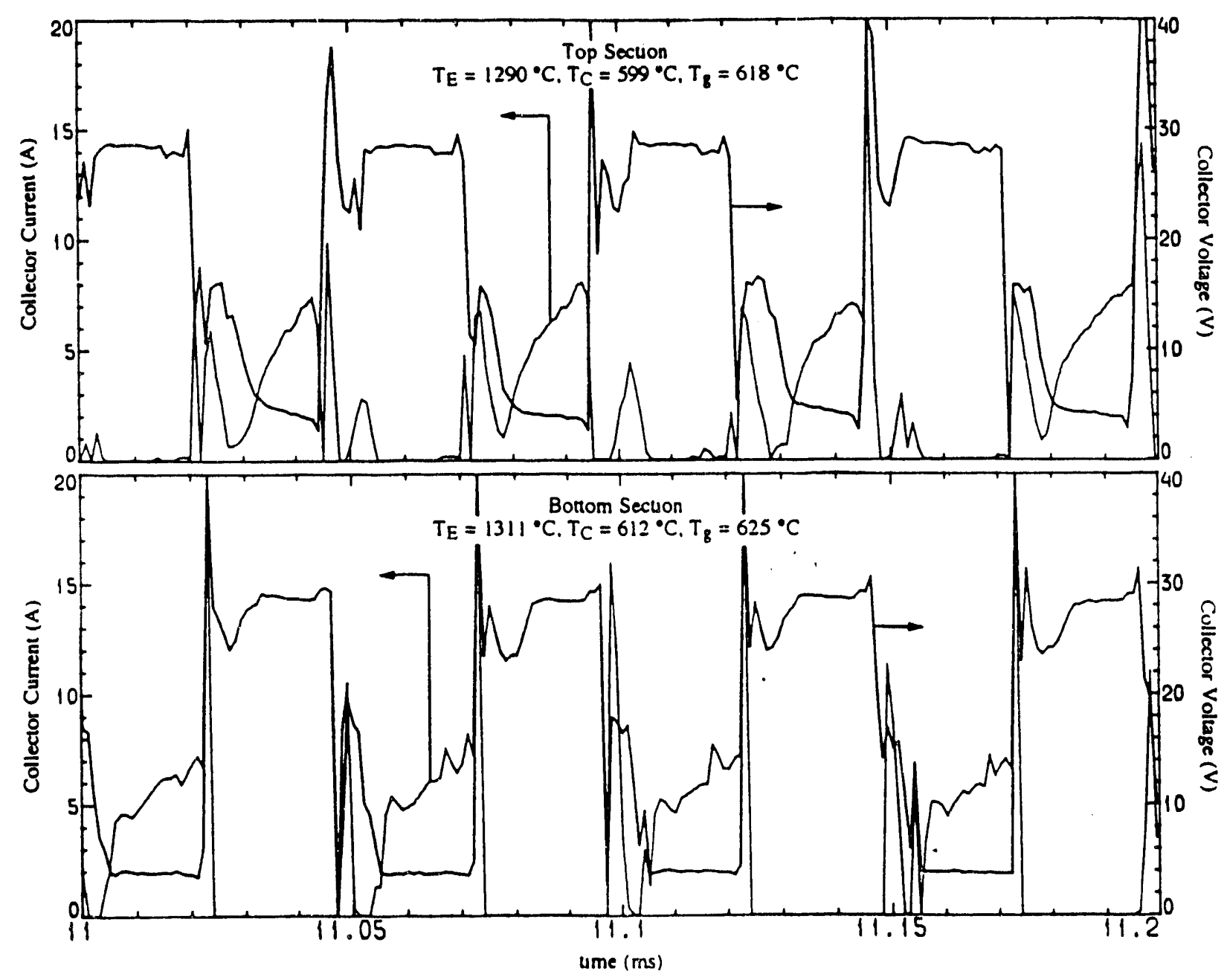

Figure 23. Measured Voltage and Current Signals with the Small Aperture Grid While Operating in the Tacitron Mode $\left(\mathrm{T}_{\mathrm{Cs}}=139^{\circ} \mathrm{C}, \mathrm{T}_{\mathrm{Ba}}=551^{\circ} \mathrm{C}\right.$, and $\left.\mathrm{f}_{\mathrm{g}}=20 \mathrm{kHz}\right)$. 


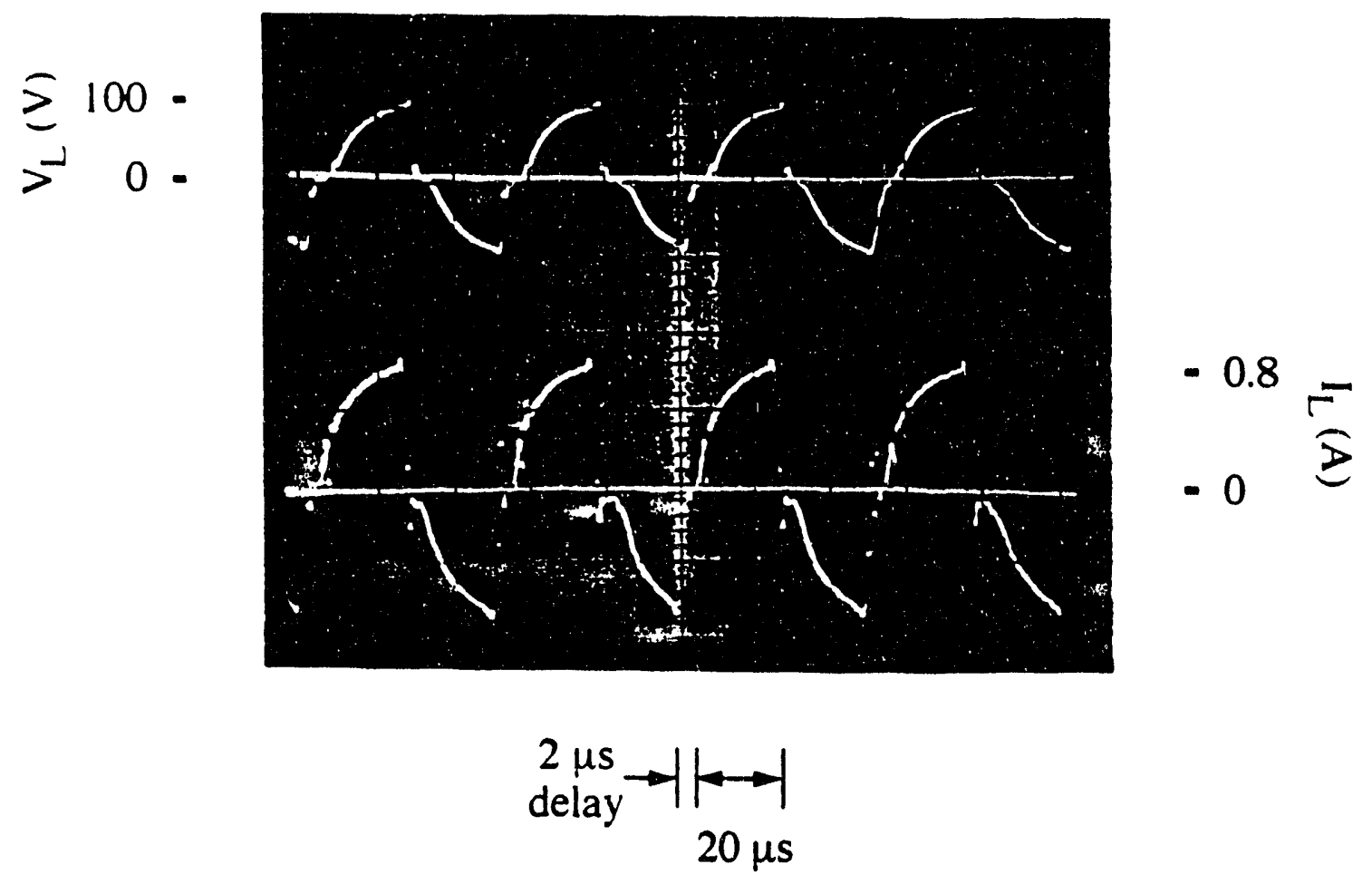

Figure 24. Measured Voltage and Current Signals with the Small Aperture Grid at the Output of the Step-Up Pulse Transformer While Operating in the Tacitron Mode $\left(\mathrm{T}_{\mathrm{Cs}}=139^{\circ} \mathrm{C}\right.$, $\mathrm{T}_{\mathrm{Ba}}=551^{\circ} \mathrm{C}$, and $\mathrm{f}_{\mathrm{g}}=20 \mathrm{kHz}$ ). 
aperture grid to $0.8 \mathrm{~A}$ at the load. At this increased current and modulation frequency the pulse shape has become even more non-square, it is almost sawtooth shaped. This affect might be alleviated somewhat by optimizing the inverter circuit to operate at $20 \mathrm{kHz}$. Presently the circuit is optimized for $4 \mathrm{kHz}$ operation.

It should be noted that in the test device, because the Cs reservoir is closer to the bottom tacitron, there is a difference in the Cs vapor pressure in the discharge gaps of the top and bottom tacitrons, which makes it difficult to find a Cs reservoir temperature that allowed stable current modulation in both devices. This difference in the Cs vapor pressure in each section, at the same reservoir temperature, could be caused by a strong $\mathrm{Cs}$ adsorption on the construction materials. Therefore, depending on the temperature in the different tacitron sections and the time during which current modulation was maintained, the Cs pressure in the inter-electrode gaps changed with time and was usually larger in the bottom section. Since stable current modulation in the tacitron inverter mode is very sensitive to the Cs vapor pressure in the tacitrons, it was difficult to find a $\mathrm{Cs}$ reservoir temperature at which stable current modulation can be maintained simultaneously in both the top and the bottom triode sections.

\section{SUMMARY AND CONCLUSIONS}

The operation characteristics of the Cs-Batacitron as a switch are investigated experimentally in three modes: (a) breakdown mode, (b) I-V mode, and (c) current modulation mode. The switching frequency, grid potentials for ignition and extinguishing of discharge, and the Cs pressure and emission conditions (Ba pressure and emitter temperature) for stable clirrent modulation are determined. The experimental data is also used to determine the off-time required for successful ignition, and the effects of the aforementioned operation parameters on the ignition duty cycle threshold for stable modulation. Based on the agreement between analysis and measurements it is concluded that at the onset of instability, leading to discharge extinguishing, the plasma in the discharge gap is highly ionized and equilibrium exists between the ion flux leaving the gap and the Cs atom flux entering the gap. Experimental results demonstrate that in the initial 
discharge ignition equilibrium occurs within several milliseconds, depending on the leakage of the ions from the discharge gap and the desorption of Cs atoms from the electrode surfaces. The time to reach equilibrium depends not only on the current density and Cs vapor pressure but also on the voltage drop during discharge; higher voltage drop increases the electron temperature resulting in a lower time of reaching equilibrium.

Because the density of heavy component in the discharge gap during current modulation is lower than at the moment of initial discharge ignition, the measured voltage drop in the I-V mode is lower than that during current modulation, at the same Cs reservoir temperature. The voltage drop strongly depends on the Cs pressure and to a lesser extent on the emission conditions. Increasing the Cs pressure and/or the emission current lowers the voltage drop but if the discharge current is kept lower that the emission current, the voltage drop during stable current modulation is constant and could be as low as $3 \mathrm{~V}$.

Results show that discharge extinguishing during current modulation occurs as a result of the decrease in the heavy component density in the gap during the discharge. Therefore, a definite correlation exists between the discharge current density, $C s$ vapor pressure, off-time, and on-time. The off-time required to replenish $\mathrm{Cs}$ atoms in the gap for subsequent ignition depends on the amplitude of the positive grid pulse, while the anode-delay time depends on both the off-time and the magnitude of the positive grid potential for ignition. In general, stable current modulation occurs at a device duty cycle $\geq 45-55 \%$. Such a duty cycle is almost independent of the modulation frequency of the grid, but increases as the grid potential for ignition or the Cs pressure is increased. Experimental results show that the net effect of Cs adsorption/desorption on the offtime for ignition during stable current modulation or on ignition in the breakdown mode is insignificant. This finding suggest that during discharge the ion flux to the surface of the electrodes does not practically influence their coverage by Cs atoms. Results also indicate that the off-time required for ignition is strongly dependent on the Cs pressure, and to a lesser extent on the emitter temperature, but it is almost independent of the $\mathrm{Ba}$ vapor pressure. 
Experiments were also conducted in which an inverter was configured by connecting two Cs-Ba tacitrons, with alternating voltage grid control, in a push-pull mode. The current and voltage characteristics of the inverter were measured in both the thyratron and the tacitron mode. In order to determine whether operating in the thyratron or the tacitron mode is more advantageous, several issues must be considered, namely: the inverter parameters, the available voltage source, and the requirements on the output voltage and current. At low source voltages, the conduction voltage drop in the tacitrons, when operating in the thyratron inverter mode, is about $1-1.5 \mathrm{~V}$ lower than in the tacitron mode. But the additional electric power needed for recharging the capacitor in the thyratron mode would have an essential influence on the inverter efficiency. If the losses associated with recharging the capacitor in the thyratron mode are less than those associated with the higher voltage drop in the tacitron mode, the thyratron mode may be more efficient. The losses associated with recharging the capacitor in the thyratron mode would increase with increased modulation frequency. On the other hand, if the source voltage is high and increasing the voltage drop by $1-1.5 \mathrm{~V}$ in the tacitron regime is a negligible fraction of the source voltage and if high operating frequencies of the inverter are desired, it is more advantageous to operate in the tacitron mode.

The inverter characteristics demonstrated in the thyratron mode include discharge current up to $20 \mathrm{~A}$, collector voltage of $30 \mathrm{~V}$, conduction voltage drop less than $3 \mathrm{~V}$, and modulation frequencies up to $10 \mathrm{kHz}$. In the tacitron mode, the inverter operation was operated at a discharge current of up to $3.5 \mathrm{~A}$, collector voltage of $25 \mathrm{~V}$, conduction voltage drop of $3-3.5 \mathrm{~V}$, and modulation frequencies up to $20 \mathrm{kHz}$. When the grid aperture diameter was reduced from $0.8 \mathrm{~mm}$ to $0.4 \mathrm{~mm}$ it was possible to operate the inverter at discharge currents up to $13.5 \mathrm{~A}$, for a collector voltage of $24 \mathrm{~V}$ and a conduction voltage drop of $4 \mathrm{~V}$.

It was shown that by increasing the discharge current the shape of the current and voltage waveforms at the load became non-square shaped. At modulation frequencies of $20 \mathrm{kHz}$, the waveforms became almost sawtooth. Also, it was shown that at higher currents, the increase in the ion leakage flux resulted in a time delay between when the positive potential is applied to the 
grid and when the tacitron breaks down, of about $10 \mu \mathrm{s}$. This anode delay time is non-existent at the lower currents for either grid.

\section{ACKNOWLEDGEMENTS}

The authors would like to thank A. Borovskikh, Y. Djashiashvili, and Y. Taldonov for the I.V. Kurchatov Institute of Atomic Energy, Moscow, Russia, for their help in the testing of the tacitron. Research sponsored by the Strategic Defense Initiative Organization, the Air Force Phillips Laboratory, and the U.S. Department of Energy University research program, under research contracts to University of New Mexico's Institute for Space Nuclear Power Studies. 


\section{REFERENCES}

1V. Z. Kaibyshev, G. A. Kuzin, and M. V. Mel'nikov, "Use of the Thermionic Converter for Regulation of Current in Electric Circuits", Soviet Physics Technical Physics, vol. 17, pp. 10061009 (1972).

2V. Z. Kaibyshev and G. A. Kuzin, "Effect of a Third Electrode on a Low-Voltage Arc", Soviet Physics Technical Physics, vol. 20, 203, (1975).

3Y. B. Kaplan, A. N. Makarov, A. M. Martsinovskii, A. V. Novikov, V. I. Serbin, B. I. Tsirkel, and V. G. Yur'ev, "Novel Low-Voltage High-Temperature Switching Element for DC-to-AC Conversion. I. Effect of a Grid on a Low-Voltage Cesium Arc", Soviet Physics Technical Physics, vol. 22, pp. 159-165 (1977).

${ }^{4}$ V.B. Kaplan, A. M. Martsinovskii, A. S. Mustafaev, V. I. Sitnov, A. Ya. Ender, and V. G. Yur'ev, "Spontaneous Current Cutoff in a High-Current Low-Pressure Cesium-Barium Discharge", Sov. Phys. Tech. Phys., vol. 24, pp. 325-328 (1979).

5J.G. Andrews and J.E. Allen, "Theory of a Double Sheath Between Two Plasmas", Proc. Roy. Soc. Lond. A., vol. 320, pp. 459-472 (1971).

${ }^{6}$ E.I. Lutsenko, N.D. Sereda, and L.M. Kontsevoi, "Investigation of Current Limitation in a Strong Current Discharge", Sov. Phys.-JETP, vol. 42, pp. 1050-1056 (1975).

7O.R. Korendo, A.K. Musin, and S.F. Utenkova, "Low-Pressure Discharge in a Hetergeneous Medium", Sov. Phys. Tech. Phys., vol. 18, pp. 1061-1066 (1974).

8I. Langmuir and H. Mott-Smith Jr., "Data on Discharge in Mercury Vapor Obtained with Cylindrical Collectors", Gen. Elect. Rev., vol. 27, pp. $762-771$ (1924).

${ }^{9}$ A.W. Hull and F.R. Elder, "The Cause of High Voltage Surges in Rectifier Circuits", J. Appl. Phys., vol. 13, pp. 372-383 (1942).

10P.C. Standgeby and J.E. Allen, "Plasma State Current Amplifier", Nat. Phys. Sci., vol. 233, pp. 26-27 (1971).

11V.Z. Kaibyshev, A. Borovskikh, Y. Djashiashvili, Y. Taldonov, M.S. El-Genk, C.S. Murray. and G.G. McDuff, "Pecularities of the Discharge Breakdown of the Cs-Ba Tacitron", The $2^{\text {nd }}$ 
Annual Conference of Space Power, (Editor, V. Z. Kaibyshev), Sukumi, Georgia, USSR (1991).

12 C.S. Murray, M.S. El-Genk and V.Z. Kaibyshev, "An Analysis of Extinguishing Characteristics of a Cs-Ba Tacitron", Proc. of the 9th Symposium on Space Nuclear Power Systems, (Editors, M. S. El-Genk and M. D. Hoover), Albuquerque, NM, January 12-16, American Institute of Physics Conf. Proc. No. 417, 1, pp. 417-427 (1992).

13B. Wernsman, M.S. El-Genk, and C. Murray, "Ignition of Cs-Ba Tacitron During Breakdown and Extinguishing Modes", Proc. of the 9th Symposium on Space Nuclear Power Systems, (Editors, M. S. El-Genk and M. D. Hoover), Albuquerque, NM, January 12-16, American Institute of Physics Conf. Proc. No. 417, 1, pp. 410-416 (1992).

14M.S. El-Genk, C.S. Murray, S. Chaudhuri, V.Z. Kaibyshev, A. Borovskikh, Y. Djashiashvili, and Y. Taldonov, "Experimental Evaluation of Cs-Ba Thermionic Switch/Inverter - Tacitron", Proc. of the $26^{\text {th }}$ IECEC Conference, American Nuciear Society, Boston, Massachusetts, vol. 3, pp. 160-165, (1991).

15 A.A.W.M Garamoon and N.A. Surplice, "The Breakdown Potential and First Ionization Coefficient in a Townsend Discharge in Caesium Vapour", J. Phys. D: Appl. Phys., vol. 6, pp. 206-211 (1972). 

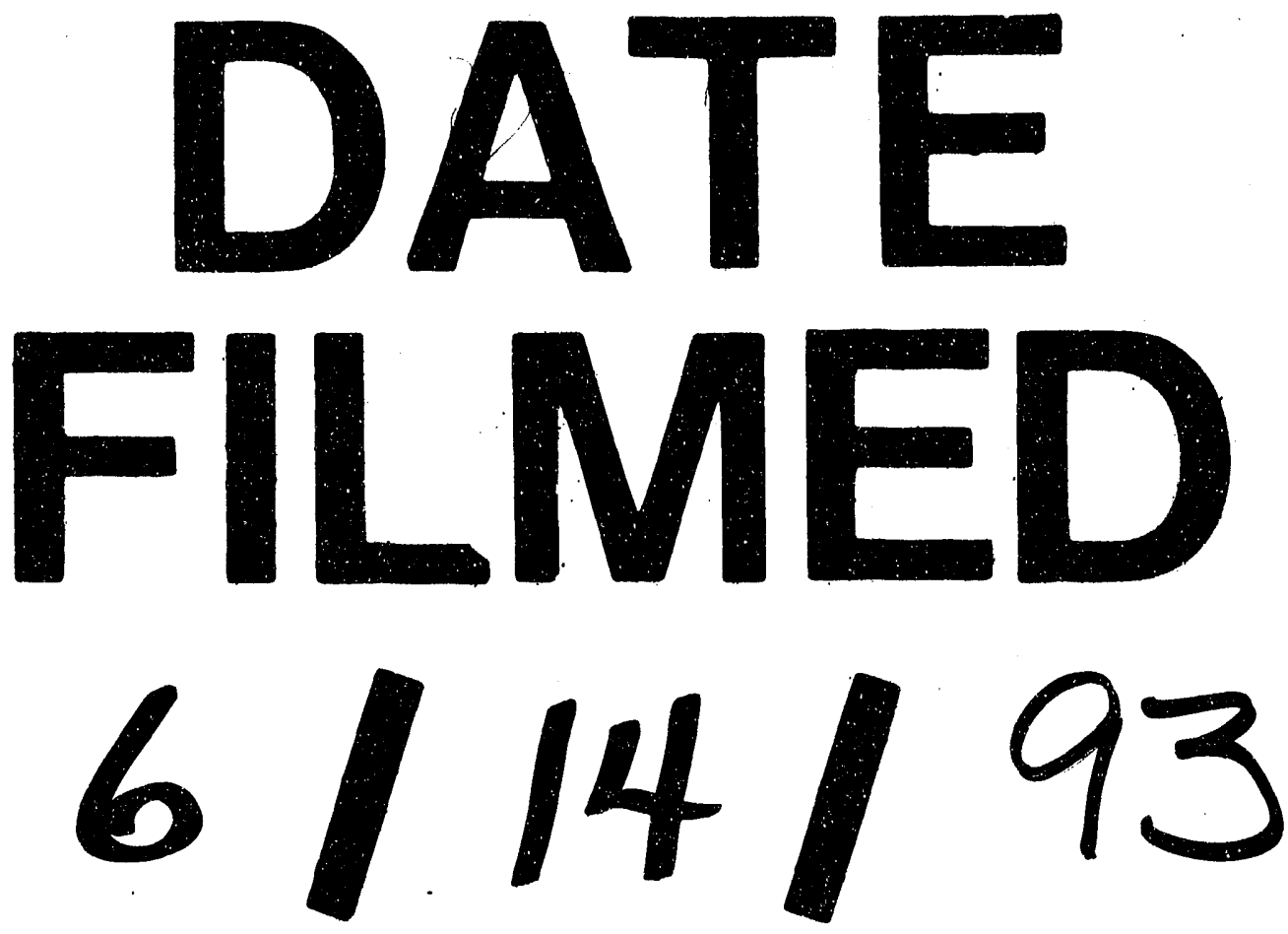


\section{.}

